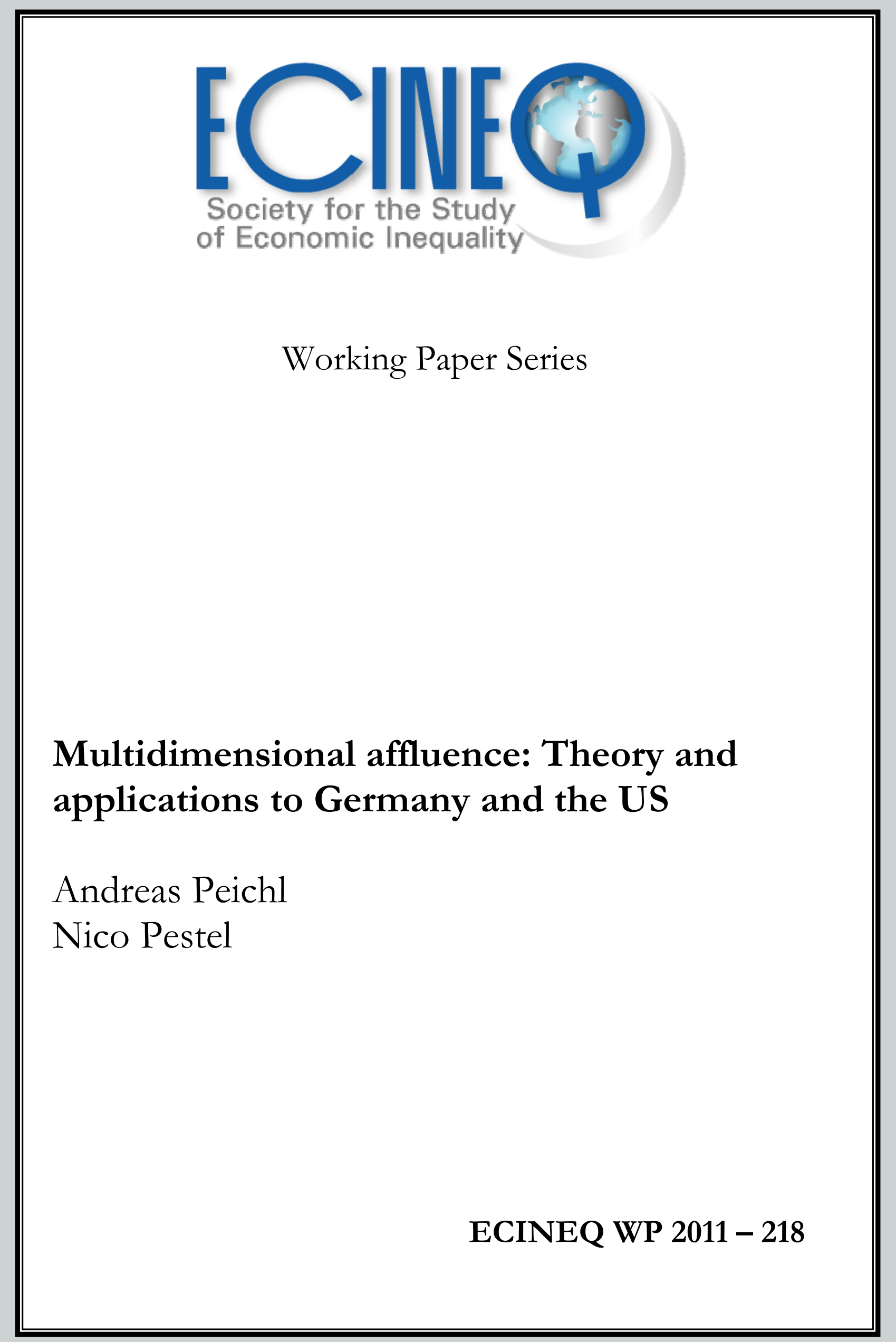




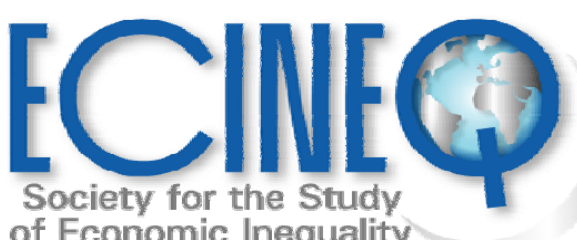

ECINEQ $2011-218$

October 2011

of Economic Inequality

www.ecineq.org

\title{
Multidimensional affluence: Theory and applications to Germany and the $\mathrm{US}^{*}$
}

\author{
Andreas Peichl ${ }^{\dagger}$ \\ Institute for the Study of Labor (IZA), \\ University of Cologne, ISER and CESifo \\ Nico Pestel \\ Institute for the Study of Labor (IZA) and University of Cologne
}

\begin{abstract}
This paper suggests multidimensional affluence measures for the top of the distribution. In contrast to commonly used top income shares, they allow the analysis of the extent, intensity and breadth of affluence in several dimensions within a common framework. We illustrate this by analyzing the role of income and wealth as dimensions of multidimensional well-being in Germany and the US in 2007 as well as for the US over the period 1989-2007. We find distinct country differences with the country ranking depending on the measure. While in Germany wealth predominantly contributes to the intensity of affluence, income is more important in the US.
\end{abstract}

Keywords: top incomes, multidimensional measurement, richness, wealth, inequality JEL classification: D31, D63, I31

\footnotetext{
* Andreas Peichl is grateful for financial support from Deutsche Forschungsgemeinschaft (DFG). We thank Joachim R. Frick, Markus M. Grabka, Thomas Piketty, Christoph Scheicher and Sebastian Siegloch as well as seminar participants at the University of Verona (Italy) and IZA in Bonn (Germany) for helpful suggestions and comments. This paper has been presented at the 10th International Meeting of the Society for Social Choice and Welfare in Moscow (Russia), the 2011 New Directions in Welfare Conference in Paris (France) and the Fourth Meeting of the Society for the Study of Economic Inequality in Catania (Italy).

† Contact details: Andreas Peichl, IZA Bonn, P.O. Box 7240, 53072 Bonn, Germany, Tel.: +49-228-3894511, Fax: +49-228-3894-510.
} 


\section{Introduction}

The top of the income distribution has recently received increased attention in the literature on economic inequality 1$]$ So far, this literature has only been concerned with a single dimension (either income or wealth) and has mainly focused on the shares of top fractiles.2 We argue that this approach should be extended for three reasons. First, neither a headcount ratio nor top shares are satisfying measures for (inequality of) economic well-being at the top because they do not account for changes in the composition or in the distribution among the top. Second, wellbeing is usually not perceived as an one-dimensional phenomenon and therefore the analysis should be extended to more dimensions, e.g. income and wealth $\mathrm{H}^{3}$ Third, analyzing top income and wealth shares separately does not reveal insights about their joint distribution.

We therefore propose a class of multidimensional affluence measures. Our approach is related to the work of Alkire and Foster (2011a), who extend the FGT poverty measures (Foster et al., 1984) to a multidimensional setting. We adopt an analogous approach and extend the one-dimensional affluence measures developed by Peichl et al. (2010). Central to this is a dual cutoff method that identifies those individuals considered to be multidimensionally affluent. Our measures do not only take into account the number of individuals' affluent dimensions, but are also sensitive to changes in achievements within each dimension. This allows to investigate inequality among "the rich" and to explicitly analyze the intensity of affluence.

We illustrate our approach using comparable micro data in order to analyze multidimensional affluence across countries (Germany and the US in 2007) and over time (the US from 1989 to 2007). Comparing these two countries is of special interest

${ }^{1}$ According to Frank (2007), John Kenneth Galbraith's famous statement that "the rich" are the most noticed and the least studied of all classes "has never been more true than today". See Atkinson and Piketty (2007); Waldenström (2009); Atkinson et al. (2011) for overviews of the top income literature.

${ }^{2}$ See e.g. Atkinson (2005); Dell (2005); Piketty (2005); Saez (2005); Saez and Veall (2005); Piketty and Saez (2006); Atkinson and Piketty (2007); Roine and Waldenström (2008); Roine et al. (2009); Roine and Waldenström (2011).

${ }^{3}$ For this reason, multidimensional measurement - particularly with regard to poverty - has received growing interest (see Atkinson, 2003, Bourguignon and Chakravarty, 2003; Alkire and Foster, 2011a; Decancq and Ooghe, 2010 Decancq and Lugo, 2011a, among others). 
since they represent two distinct welfare state regimes and exhibit different trends in income inequality (Fuchs-Schündeln et al., 2010; Heathcote et al., 2010). Unfortunately, administrative data comprising information on both income and wealth is not available. Hence, we must rely on survey data for our empirical illustration. We extensively discuss issues arising from this and compare our results to findings from German tax return data.

Besides income, we consider wealth as an additional dimension in order to capture the breadth of affluence. $4^{4}$ This is important, since the rich are not a homogenous group, especially in terms of income and wealth composition Atkinson, 2008; Waldenström, 2009). For instance, a differentiation can be made between the high-skilled "working rich" earning high salaries and the "coupon clippers" with large wealth holdings and capital income (Kopczuk and Saez, 2004).5 Wealth is typically more unequally distributed than income (Jenkins and Jäntti, 2005; Davies et al. 2009) and - although positively - not perfectly correlated with it (Kennickell, 2009). Therefore, analyzing the joint distribution reveals additional insights about the composition of the top of the distribution and allows us to quantify the contribution each dimensions to multidimensional affluence 6

Our empirical analysis yields the following results. We find that the (rank) correlation between income and wealth is far from perfect in both countries and particularly weak in Germany. The ranking of the two countries in terms of affluence depends on the choice of multidimensional measure. When emphasizing large levels of income and/or wealth of a small group of individuals and hence inequality among

${ }^{4}$ In their report on the measurement of economic performance and social progress Stiglitz et al. (2009) write that "income and consumption are crucial for assessing living standards, but in the end they can only be gauged in conjunction with information on wealth" (p. 13). Wealth serves as a source of income, utility and power as well as social status (Frick and Grabka, 2009) and helps to stabilize consumption over time (Wolff and Zacharias, 2009; Michelangeli et al., 2011). In addition, wealth and income represent distinct dimensions of satisfaction with life (D'Ambrosio et al., 2009).

5 The composition of resources commanded by the top might help to understand what drives trends and differences in inequality. One finding of the top income literature is that labor income nowadays plays a much bigger role at the very top of the income distribution than at the beginning of the $20^{\text {th }}$ century indicating greater mobility. However, Edlund and Kopczuk (2009) and Piketty (2011) provide evidence that capital income from inherited wealth can be expected to become more important in the future.

${ }^{6}$ In fact, marginal distributions can be shaped very differently. For example, Sweden has low income inequality but at the same time very high wealth inequality (Roine and Waldenström, 2008; OECD, 2008, Jäntti et al., 2008; Roine and Waldenström, 2009). 
the rich population, the US clearly is richer than Germany as income and wealth are much more concentrated at the very top. This type of affluence increased in the US between 1989 and 2007. In contrast, when putting more emphasis on the homogeneity of the rich population, it turns out that affluence is slightly larger in Germany. This level has remained almost constant in the US throughout a period of nearly two decades. Our findings confirm previous results highlighting the tremendous increases at the very top (Atkinson et al. 2011). Furthermore, we find that in Germany wealth predominantly contributes to intense affluence while income is more important in the US.

The paper is organized as follows: Section 2 introduces the concept of measuring multidimensional affluence before we describe the data in section 3 . Our results are presented in section 4 and discussed in section 5 . Section 6 concludes.

\section{Theory: Measuring Multidimensional Affluence}

While an extensive literature on poverty indices exists, little research has yet been carried out on the measurement of richness. Atkinson (2007) identifies three main reasons why researchers and policy-analysts should care particularly about "the rich": their command over resources (significant taxable capacity 7 ), their command over people (income and wealth as sources of power) and their global significance. Waldenström (2009) argues that the affluent are an important group in society since their resources are important sources of variation in measures of inequality.

\subsection{One-dimensional affluence}

Measurement of affluence at the top of the income distribution so far has either focussed on headcount ratios or top income shares. We argue, however, that this approach should be extended 8 A headcount ratio is only concerned with the number of people above a certain cutoff and an income change will not affect this index if

\footnotetext{
7 With respect to taxation, the top of the income distribution is of special interest since its share of taxes paid is disproportionately large in most countries (OECD, 2008, p. 106 f.).

${ }^{8}$ For poverty more sophisticated measures have been available for a long time (Foster et al., 1984). See Eisenhauer (2011) for an overview of richness measurement.
} 
nobody crosses the threshold. A top income share analyzes the amount of income for a fixed number of people without accounting for changes in the composition of the population nor changes in the distribution of income among the top.

Peichl et al. (2010) propose a class of affluence measures analogously to wellknown measures of poverty (Foster et al. 1984$)$. The general idea is to take into account the number of affluent people (composition of rich subpopulation) as well as the intensity of affluence (distribution among the rich). An index of affluence is constructed as the weighted sum of the individual contributions. The weighting function is supposed to have some desirable properties, which are derived following the literature on axioms for poverty indices. Thereby, the transfer axiom of poverty measurement can be translated to affluence in two different ways:

- Transfer axiom T1 (concave): an affluence index shall increase when a rankpreserving progressive transfer between two affluent persons takes place.

- Transfer axiom T2 (convex): an affluence index shall decrease when a rankpreserving progressive transfer between two affluent persons takes place.

The question behind the definition of these opposite axioms is: shall an index of affluence increase if a billionaire gives an amount $x$ to a millionaire $(T 1)$, or if the millionaire gives the same amount $x$ to the billionaire (T2). This question cannot be answered without normative judgement. Peichl et al. (2010) therefore define two classes of affluence indices which either fulfil T1 or T2.

Let $y_{i}$ be the income of individual $i, \gamma$ the affluence line and $r=\#\left\{i \mid y_{i}>\right.$ $\gamma, i=1, \ldots, n\}$ the number of affluent persons. For $T 1$ the relative incomes $y_{i} / \gamma$ have to be transformed by a function that is concave on $(1, \infty)$. Peichl et al. (2010) use $f(x)=\left(1-\frac{1}{x^{\beta}}\right) \cdot \mathbf{1}_{x>1}$ where $\beta>0$ and $\mathbf{1}_{x>1}$ denotes an indicator function taking on values of one if $x>1$ and zero otherwise:

$$
R_{\beta}^{C h a}(\mathbf{y}, \gamma)=\frac{1}{n} \sum_{i=1}^{n}\left(1-\left(\frac{\gamma}{y_{i}}\right)^{\beta}\right)_{+}, \beta>0 .
$$

The subscript "+" indicates that the expression in brackets must be greater than or equal to zero. For T2, Peichl et al. (2010) use $f(x)=(x-1)^{\alpha}$ for $x>1$, with 
$\alpha>1$, to obtain an affluence index that resembles the FGT index of poverty:

$$
R_{\alpha}^{F G T, T 2}(\mathbf{y}, \gamma)=\frac{1}{n} \sum_{i=1}^{n}\left(\frac{y_{i}}{\gamma}-1\right)^{\alpha} \cdot \mathbf{1}_{y_{i}>\gamma}=\frac{1}{n} \sum_{i=1}^{n}\left(\left(\frac{y_{i}-\gamma}{\gamma}\right)_{+}\right)^{\alpha}, \alpha>1
$$

The choice of transfer axiom depends on the research question. A more equal distribution among the rich will lead to a more homogenous group, which could allow them to better coordinate in pursuing their interests. If one is interested in this case, the concave approach is more appropriate. In contrast, the convex measure reflects inequality among the rich and the concentration of resources at the very top.

\subsection{Multidimensional affluence}

The dual cutoff method of multidimensional affluence works as follows: In a first step, an individual is considered as dimension-specific affluent when its achievement in a specific dimension of well-being exceeds the respective cutoff value. In a second step, we define which individuals (among those who are affluent with respect to at least one dimension) are considered to be affluent in a multidimensional sense with the help of a counting methodology (Atkinson, 2003; Alkire and Foster, 2011a). An affluent individual is defined to be multidimensionally affluent, if the number of its affluence counts across all dimensions is greater than or equal to a certain threshold (second cutoff). After having identified "the rich", their individual achievements are aggregated to single-value measures of multidimensional affluence.

Dimension-specific affluence. The number of individuals in the population is denoted with $n$, while $d \geq 2$ denotes the number of dimensions of affluence under consideration. Define the matrix of achievements with $\mathbf{Y}=\left[y_{i j}\right]_{n \times d}$, where $y_{i j}$ denotes the achievement of individual $i \in\{1, \ldots, n\}$ in dimension $j \in\{1, \ldots, d\}$. For each dimension $j$, there is some cutoff value $\gamma_{j}$. Hence, $\gamma$ denotes a $1 \times d$ vector of dimension-specific cutoffs. With the help of this vector, it is possible to identify, whether individual $i$ is affluent with respect to dimension $j$ or not. Therefore, define an indicator function $\theta_{i j}$, which equals 1 if $y_{i j}>\gamma_{j}$ and 0 otherwise and with its help construct a $0-1$ matrix of dimension-specific affluence $\Theta^{0}=\left[\theta_{i j}\right]_{n \times d}$, where each 
row vector of $\Theta^{\mathbf{0}}$, denoted with $\theta_{\mathbf{i}}$, is equivalent to individual $i$ 's affluence vector. Hence, this yields us a vector of affluence counts, denoted $\mathbf{c}=\left(c_{1}, \ldots, c_{n}\right)^{\prime}$. Its elements $c_{i}=\left|\theta_{i}\right|$ are equal to the number of dimensions, in which an individual $i$ is defined to be affluent.

In case of cardinal variables in the achievement matrix $\mathbf{Y}$, it is possible to construct matrices that, in addition, do not only provide the information whether an individual $i$ is affluent with respect to dimension $j$ or not, but also inform about the intensity of affluence associated with the dimension under consideration. Thereby, one can distinguish the concave and the convex case (see above). If we are interested in the convex case, we look at the following matrix for a given cutoff $\gamma_{j}$ :

$$
\boldsymbol{\Theta}^{\alpha}=\left[\left(\frac{y_{i j}-\gamma_{j}}{\gamma_{j}}\right)_{+}^{\alpha}\right]_{n \times d} \text { for } \alpha \geq 1
$$

In the concave case we have

$$
\boldsymbol{\Theta}^{\beta}=\left[\left(1-\left(\frac{\gamma_{j}}{y_{i j}}\right)^{\beta}\right)_{+}\right]_{n \times d} \text { for } \beta>0 .
$$

Again, the subscript " + " indicates that the entries of matrices $\Theta^{\alpha}$ and $\Theta^{\beta}$ respectively must be greater than or equal to zero. The parameters $\alpha$ and $\beta$ are sensitivity parameters for the intensity of affluence. For larger (smaller) values of $\alpha(\beta)$ more weight is put on more intense affluence. $!^{9}$

In addition to the difference with respect to the normative judgement of progressive transfers between affluent individuals the distinction between the concave and convex cases respectively helps to understand what drives inequality at the top of the joint distribution of dimensions.

Multidimensional measures. We now define multidimensional affluence with the help of the dual cutoff method of identification. For an integer $k \in\{1, \ldots, d\}$

\footnotetext{
${ }^{9}$ Note that $\Theta^{0}$ is simply a special case of $\boldsymbol{\Theta}^{\alpha}$ for $\alpha=0$ and of $\boldsymbol{\Theta}^{\beta}$ for $\beta \rightarrow \infty$ respectively. For $\alpha=1$ the function $\left(y_{i j}-\gamma_{j}\right) / \gamma_{j}$ is just linear in $y_{i j}$.
} 
define the identification method as

$$
\phi_{i}^{k}\left(y_{i}, \gamma\right)= \begin{cases}1 & \text { if } c_{i} \geq k \\ 0 & \text { if } c_{i}<k\end{cases}
$$

This yields a $0-1$ vector $\phi^{\mathbf{k}}$ with entries $\phi_{i}^{k}$ equal to one if the number of affluent dimensions of individual $i$ is not less than $k$, and is zero otherwise. In other words, individual $i$ is considered to be multidimensionally affluent, if the number of dimensions in which its achievement is considered as affluent attains a certain threshold 10 So, we can define the subset of multidimensionally affluent individuals among the whole population as $\Phi_{k}=\left\{i: \phi_{i}^{k}\left(y_{i}, \gamma\right)=1\right\} \subseteq\{1, \ldots, n\}$. The number of affluent individuals is denoted with $s^{k}=\left|\Phi_{k}\right| \cdot 11$

Since, according to the focus axiom, a measure of affluence must take into account information on the affluent only, we also replace the elements of the vector of affluence counts $\mathbf{c}$ with zero, when the number of affluence counts of the according individual $i$ does not attain the threshold $k$. Formally:

$$
c_{i}^{k}= \begin{cases}c_{i} & \text { if } c_{i} \geq k, \\ 0 & \text { if } c_{i}<k\end{cases}
$$

This yields the vector $\mathbf{c}^{\mathbf{k}}=\left(c_{1}^{k}, \ldots, c_{n}^{k}\right)^{\prime}$, which contains zeros for those not considered to be affluent and the number of dimensions, in which the affluent individuals are considered as affluent. That is, even in case of an individual which is affluent in several dimensions, its entry in $\mathbf{c}^{\mathbf{k}}$ nevertheless might be zero if its number of affluent dimensions is smaller than the threshold $k$.

In order to obtain matrices that provide information on affluent individuals only, we replace the row $i$ of $\boldsymbol{\Theta}^{\alpha}$ and $\boldsymbol{\Theta}^{\beta}$ respectively with vectors of zeros, whenever

10 An individual $i$ can be affluent in one or more dimensions and, at the same time, not be multidimensionally affluent (when it holds that $c_{i}<k$ ), while a multidimensionally affluent person by definition is always affluent in at least $k$ dimensions. Here, we assume equal weighting of dimensions. It is possible to allow for different weights (see Appendix C).

11 Hereby, one can think of two extreme cases. First, for $k=1$, person $i$ is multidimensionally affluent when she is considered as affluent in at least one single dimension (union approach). Second, for $k=d$, she is only considered as affluent, if she is affluent in all dimensions (intersection approach). In case of $1<k<d$ we have an intermediate approach (Alkire and Foster, 2011a). 
it holds that $\phi_{i}^{k}\left(y_{i}, \gamma\right)=0$. Formally, define

$$
\begin{aligned}
& \boldsymbol{\Theta}^{\alpha}(\mathbf{k})=\left[\left(\frac{y_{i j}-\gamma_{j}}{\gamma_{j}}\right)^{\alpha} \cdot \phi_{i}^{k}\left(y_{i}, \gamma\right)\right]_{n \times d} \text { and } \\
& \boldsymbol{\Theta}^{\beta}(\mathbf{k})=\left[\left(1-\left(\frac{\gamma_{j}}{y_{i j}}\right)^{\beta}\right) \cdot \phi_{i}^{k}\left(y_{i}, \gamma\right)\right]_{n \times d} .
\end{aligned}
$$

Now we are able to define measures of multidimensional affluence based on the definitions that were introduced in the previous two subsections. In order to derive a first multivariate measure of affluence, define the headcount ratio $(H R)$ as

$$
H R^{k}=\frac{s^{k}}{n}
$$

which is simply the proportion of affluent individuals among total population. The average affluence share $\left(A A S^{k}\right)$ reads

$$
A A S^{k}=\frac{\left|\mathbf{c}^{\mathbf{k}}\right|}{s^{k} \cdot d}
$$

where $\left|\mathbf{c}^{\mathbf{k}}\right|$ denotes the number of affluence counts among the multidimensionally affluent population. The average affluence share is hence equal to the relation of this number to the maximum number of affluence counts that would be observed when all affluent individuals were affluent among all dimensions and it holds $k / d \leq A A S^{k} \leq$ 1. For a given number of dimensions under consideration, the value of $A A S^{k}$ is close to one, when there is a very strong correlation of affluence across dimensions, i.e. those who are affluent tend to be affluent in all dimensions. The value becomes smaller if the number of dimensions decreases. It reaches its minimum value of $1 / d$, when all affluent individuals are only affluent with respect to one single dimension.

Now, we can define a first measure of multidimensional affluence by simply multiplying the headcount ratio and the average affluence share. The dimension adjusted headcount ratio is defined as

$$
R_{H R}^{M}(k)=H R^{k} \cdot A A S^{k}=\frac{\left|\mathbf{c}^{\mathbf{k}}\right|}{n \cdot d},
$$

which is equal to the proportion of the total number of affluence counts to the maxi- 
mum number of affluence counts that one would observe when every single individual in the population under consideration would be affluent with respect to every single dimension. ${ }^{12}$ Contrary to the simple headcount ratio $H R$, the measure $R_{H R}^{M}$ satisfies the property of dimensional monotonicity, which requires that a measure of multidimensional affluence increases (decreases) when a affluent individual $\left(c_{i} \geq k\right)$ becomes (is no more) affluent in some dimension. That is why the $A A S$ is incorporated in $R_{H R}^{M}$. However, the dimension adjusted headcount ratio does not satisfy the property of monotonicity, i.e. $R_{H R}^{M}$ does not necessarily increase (decrease) when the achievement $y_{i j}$ of a affluent individual $i$ in dimension $j$ increases (decreases) ${ }^{13}$ Hence, it only reveals information about the width and not the depth of affluence.

The following additional measures of multidimensional affluence by contrast do satisfy the monotonicity property. Again, one can distinguish between a convex and a concave measure respectively. The dimension adjusted multivariate affluence measures are defined as

$$
R_{l}^{M}(k)=H R^{k} \cdot A A S^{k} \cdot \frac{\left|\Theta^{\mathbf{l}}(\mathbf{k})\right|}{\left|\mathbf{c}^{\mathbf{k}}\right|}=\frac{\left|\Theta^{\mathbf{l}}(\mathbf{k})\right|}{n \cdot d}
$$

for $l \in\{\alpha, \beta\}$ and hence are equal to the sum of the elements of the matrices $\boldsymbol{\Theta}^{\alpha}(\mathbf{k})$ and $\Theta^{\beta}(\mathbf{k})$ divided by the value $n \cdot d$ respectively. ${ }^{14}$

Since we are interested in analyzing the role of dimensions (especially income and wealth) with respect to the measurement of multidimensional affluence, it seems helpful to formally disentangle the dimensions-specific contributions. Therefore, we rewrite (11) as

$$
R_{l}^{M}(k)=\frac{\left|\Theta^{\mathbf{l}}(\mathbf{k})\right|}{n \cdot d}=\frac{\sum_{j=1}^{d}\left|\theta_{\mathbf{j}}^{\mathbf{l}}(\mathbf{k})\right|}{n \cdot d}=\frac{1}{d} \cdot \sum_{j=1}^{d} \frac{\left|\theta_{\mathbf{j}}^{\mathbf{l}}(\mathbf{k})\right|}{n}=\frac{1}{d} \cdot \sum_{j=1}^{d} \boldsymbol{\Pi}_{\mathbf{j}}^{\mathbf{l}}(\mathbf{k})
$$

12 Hence, the nomenclature of a headcount ratio is somewhat misleading. However, in order to remain consistent with the literature on multidimensional poverty (Alkire and Foster, 2011a) we stick to this naming. Moreover, the measure $R_{H R}^{M}$ is the multidimensional analogue to the one-dimensional headcount ratio.

${ }^{13}$ It does so only marginally around dimension-specific thresholds $\gamma_{j}$.

14 Note that the concave measure $R_{\beta}^{M}$ is normalized between zero and one, while the convex measure $R_{\alpha}^{M}$ is not. Although one would prefer to have normalized measures only, this is not possible in the convex case in general without violating the monotonicity axiom. Hence, the choice of $R_{\alpha}^{M}$ implies a certain normative view, since it emphasizes intense rather than moderate affluence. 
for $l \in\{\alpha, \beta\}$. Hence, $\boldsymbol{\Pi}_{\mathbf{j}}{ }^{l}(k)$ denotes the contribution of each dimension $j$ multiplied by the total number of dimensions $d$. More intuitively, it is equal to the proportion of individuals that are multidimensionally affluent and affluent with respect to dimension $j$ at the same time. The simple mean of all these contributions over the $d$ dimensions yields the overall multidimensional affluence measure $R_{l}^{M}$. One can show that the proportional contribution of dimension $j$ to the overall measure $R_{l}^{M}$, denoted with $\pi_{j}^{l}(k)$, can be written as

$$
\pi_{j}^{l}(k)=\frac{\left|\theta_{\mathbf{j}}^{\mathbf{l}}(\mathbf{k})\right|}{\left|\Theta^{\mathbf{l}}(\mathbf{k})\right|} .
$$

Obviously, it holds that $\sum_{j=1}^{d} \pi_{j}^{l}(k)=1$. Hence, it is possible to decompose the measures proportionally into the contributions of the single dimensions.

\section{Empirical Application}

With respect to measurement of affluence, the representativeness of individuals with (very) high income and wealth levels in the data at hand clearly is an issue. Usually, survey data are less representative at the tails of the income distribution because of small numbers of observations (Burkhauser et al., 2011a b). Both datasets we use address this issue.

\subsection{Data}

SOEP. The German Socio-Economic Panel Study (Wagner et al., 2007; SocioEconomic Panel, 2010) is a panel survey of households and individuals in Germany that has been conducted annually since 1984 . We use the 2007 wave of the SOEP with information of 18,773 individuals (aged 17+) in 10,553 households. In order to improve its "statistical power" and the reliability of statements referring to high incomes (and hence affluence), an additional sample of high income households was included into the SOEP since wave 2002. This increased the number of observations within the top $2.5 \%$ of the income distribution considerably and hence reduced potential bias due to poor representativeness of affluent households. Since 
these additional observations were oversampled, population weights were adjusted accordingly to make the data representative for the German population (Frick et al. 2007). The 2002 and 2007 waves of the SOEP contain additional information on wealth that was surveyed in supplementary questionnaires (Frick et al., 2007; Frick and Grabka, 2009).15 The SOEP income data has been validated against administrative tax data and was found to perform reasonably well up to the top $1 \%$ of the income distribution (Bach et al., 2009). Nevertheless, we perform a robustness check using German tax micro data. Unfortunately, these data do not comprise information on wealth holdings and we have to construct and impute this information. Furthermore, it is not allowed to match tax data with SOEP data due to German data protection regulations.

SCF. The Survey of Consumer Finances (SCF) is a triennial survey of US families with a special focus on wealth holdings. The 2007 wave of the SCF contains information on 4,422 families with a total of 11,199 members. They were sampled in two steps: First, a standard geographically based random sample and, second, a special oversampling of very wealthy families. Similar to the SOEP sampling weights make the respondents representative for the US population and missing data are imputed. The SCF provides detailed information on family income, balance sheets, use of financial services as well as pensions, labor force participation and demographic characteristics (Bucks et al., 2009).

\subsection{Dimensions}

Income. Our income measure contains market income from labor as well as private transfers and pensions from all household or family members Grabka, 2007; Bucks et al., 2009). Since we are interested in the joint distribution of income and wealth, we do not consider income from assets, such as payments from interest, dividends or capital gains in order to avoid "double counting". Income flows from a stock of

${ }^{15}$ Different from most other surveys that provide information on wealth, the SOEP data were collected at the individual level rather than on the household level. In order to handle the problem of measurement error arising from item or unit non-response, the SOEP provides editing and multiple imputation procedures that are described in detail by Frick et al. (2007). 
assets and the stock itself are highly correlated and the probability of being affluent in both income and wealth at the same time can be assumed to be quite high when taking capital income into account.

Wealth. While income can be defined as the "increase in a person's command over resources during a given time period" one can view wealth as "a person's total immediate command over resources" (Cowell, 2008). The requirement of immediate command refers to a notion of marketability of an individual's wealth stock. This can be seen as appropriate with respect to financial assets and (to a lesser extent) to housing or business property. Hence, our basic measure of individual wealth aggregates the following components: owner-occupied housing and other property (net of mortgage debt), financial assets, business assets, tangible assets, private pensions net of consumer credits and other debt.

Cutoffs. Defining the cutoffs which separate the population into affluent and nonaffluent individuals with respect to the dimensions under consideration is crucial for the empirical analysis. Although there are several ways to draw a poverty line (relative vs. absolute), the underlying principle - a poor person does not meet a certain level of subsistence, while a non-poor one does - is uncontroversial. With respect to the upper tail of the distribution this is less clear. The decision how to define cutoffs is up to the researcher and has to be based on normative grounds.

The standard approach in the literature is to fix the proportion of the affluent population (e.g. the top $p \%$ of the distribution, see references in footnote 2 and Cowell, 2011). For example, in research on the "middle class" it is common to define the middle to comprise the second to fourth income quintiles (Atkinson and Brandolini, 2011). Following this approach, we set the cutoff at the $80 \%$-quantile (we check the sensitivity of the results with respect to the cutoff later by looking at the top $10 \%$, top $5 \%$ and top 1\%). By definition, the one-dimensional headcount ratios then equal $20 \%$ but the multidimensional headcount does not necessarily need to take on the same value, since it depends on the joint distribution of both dimensions. Moreover, since both income and wealth usually exhibit distinct profiles over the life cycle (see Figure B.1), we let the 80\%-cutoffs vary by age of the household head 
and distinguish three age groups (head aged $\leq 29,30-59$ and $\geq 60){ }^{16}$

Descriptives. In order to make individuals with different household sizes comparable to each other we equivalize both income and wealth levels with the common square root scale. We express income and wealth in 2007 PPP US-Dollars. In Table A.1 we present our results on mean and median income and wealth respectively as well as the age group-specific cutoffs. Wealth and income are converted to constant US dollars using the Consumer Price Index (CPI-U) available from the Bureau of Labor Statistics. Furthermore, since we are interested in affluence and hence the top of the income and wealth distribution, we disregard any adjustments to the data with respect to extreme upper values (like top-coding or trimming).

Mean equivalent market income in the US equals about 45,000 USD and hence is nearly twice the level in Germany (24,000 USD), whereas - due to the more skewed distribution - the US median value (27,000 USD) is only somewhat larger than in Germany (20,500 USD). The age-specific cutoffs for the youngest group (head aged below 30) are quite similar and differ more for the older age groups, particularly for the group of 60 years and above. For the latter, the US value exceeds twice the German value. Moreover, the age group-specific distributions reveal a typical lifecycle profile: the $80 \%$-quantiles increase by age from the youngest to the medium group but decrease again for the oldest (also see Figure B.1). This pattern is more pronounced in Germany, where the cutoff for the group of 60 and older is only half the level of the youngest group. This is due to the fact that we rely on market incomes. Consumption resources of Germans above retirement age however heavily depend on old-age benefits from public pensions which are not included in our income definition. For the US, we find that the youngest and oldest groups exhibit nearly identical cutoff levels of around 36,000 USD.

Turning to the wealth distributions, we find that overall mean equivalent wealth in the US is about 356,000 USD and hence is almost three times as large as in Germany (127,000 USD). Median wealth is rather low in Germany (42,000 USD)

\footnotetext{
16 Another way of defining a cutoff analogously to standard practice in poverty research is to set the cutoff at a multiple of the median value of the respective distribution. For instance, Peichl et al. (2010) choose an upper threshold of $200 \%$ of the median.
} 
and less than one third of mean wealth. Although being significantly larger than the German median wealth level, the US median wealth of around 70,000 USD is only about one fifth of the mean. Wealth distributions in both countries are also characterized by a specific pattern over the life cycle: The cutoffs for the age groups increase monotonically and the slope is much steeper in the US. While the youngest group differs only by about 10,000 USD, the cutoff for the oldest group is more than twice as large in the US compared to Germany.

\section{Results}

\subsection{Shares, correlations and one-dimensional affluence}

Income and wealth shares. In Figure B.2 we present our estimates of income and wealth shares of the distributions' top $10 \%, 5 \%$ and $1 \%$ fractiles. The upper graph shows the shares of total income and wealth belonging to top fractiles of each dimension separately. Although we apply a slightly different concept (equivalence weighting) our results are in line with previous findings of the top income literature and further studies reporting top shares ${ }^{17}$ For Germany, we find income shares of $6.2-32.1 \%$ for the top $1-10 \%$ of the income distribution. The wealth shares vary between $21 \%$ and $55 \%$. Compared to Germany, top income and wealth shares are significantly larger in the US. The difference varies between 13 and 20 percentage points. The top $10 \%$ of the US income distribution account for $46.5 \%$ of total income, the top $1 \%$ for $18.7 \%$. The concentration of resources in terms of wealth is even larger. The top decile commands more than 70\%. Most of this share is concentrated in the top $5 \%$ of the wealth distribution, almost half of it in the top percentile. The two other graphs take into account the joint distribution of income and wealth respectively. The middle graph shows the shares of each dimension in the top fractiles of the other dimension. This means, the left (right) hand side of this graph shows the income (wealth) share of the top fractiles in the wealth (income) distribution. For example, the top decile of the US wealth distribution receives about

${ }^{17}$ See Kopczuk and Saez (2004); Dell (2005); Kennickell 2009); Frick and Grabka (2009); Atkin-
son et al. (2011).


$37 \%$ of total income, while the top $10 \%$ in income command more than $50 \%$ of wealth holdings. In general, the shares are somewhat smaller compared to the shares found for the marginal distributions, especially for Germany. Finally, the lower graph presents the shares of the joint top fractiles. For instance, those who are in the top percentiles of both the income and wealth distribution in Germany have $1.5 \%$ of total income and $5.5 \%$ of total wealth. Interestingly, the income shares of the joint top fractiles are only marginally above their population shares, which would imply an almost equal distribution. The joint top decile owns less than one fifth of total German wealth (18.5\%). The results for the US are much larger, between 2.5 and eight times the shares in Germany: The joint top decile has one third of income and half of the wealth. These findings indicate that economic resources are much more concentrated in the US than in Germany. Generally speaking, "the rich" in Germany have either high income or wealth, while in the US they tend to have both.

Rank correlations. One motivation for proposing a measure of multidimensional affluence with an application to income and wealth is the fact that looking at the distribution of one dimension only is not sufficient to capture the distribution of economic well-being within a given population in general. That is why we take a closer look at the relationship between the two dimensions under consideration. In Figure B.3 we show results for the correlation coefficient as well as for Spearman's rank correlation coefficient. It turns out that individual positions within the marginal distributions are far from perfectly correlated. This is especially true for Germany, where we find a value of 0.28 for the total population. The correlation is 0.2 . The rank-correlation index even takes on a slightly negative value $(-0.1)$ and a correlation coefficient of below 0.1, when restricting the sample to individuals with at least one affluence count. For the multidimensionally affluent (i.e. affluent in both dimensions) we find a positive but rather small number of 0.2 . This suggests that the rank of an individual within either the income or the wealth distribution is quite a poor predictor for the rank within the other marginal distribution. Our findings for the US however suggest a distinctly stronger relationship between positions in the income and wealth distributions respectively. The rank-correlation for the total population is 0.6 , whereas we find 0.54 for the subpopulation with at least one af- 
fluent count and 0.76 for the very top with income and wealth levels both exceeding the cutoffs. Nevertheless, the relationship between income and wealth positions is far from perfect in both countries.

One-dimensional affluence. In Table A.2 we list several distributional indicators for the dimensions under consideration, focussing on one-dimensional affluence measures as well as the Gini coefficient as a standard measure of inequality. Consistent with other cross-country analysis, we find larger levels of market income inequality in the US compared to Germany (Gini: 0.56 vs. 0.42) and higher levels of wealth inequality: In the US the Gini coefficient is 0.8 and 0.65 in Germany. The one-dimensional headcount ratios for affluence by definition equal 0.2 since we set the cutoff levels to the $80 \%$-quantiles. However, we find differences for the other affluence indicators taking into account inequality among the affluent subpopulation. The convex affluence measures $\left(R_{\alpha}\right)$ for both income and wealth are larger in US than in Germany. In particular for $\alpha=2$, an index emphasizing extreme affluence, we find huge values of 10.5 and 7.8 for the US compared to 0.4 and 1.6. Hence, there is much more inequality among the very top of the distributions in both dimensions. Interestingly, the concave measures $\left(R_{\beta}\right)$ turn out to be larger in Germany, which indicates that high income and wealth are more concentrated around the cutoff.

\subsection{Multidimensional affluence and its contributions}

Germany vs. the US in 2007. In Table A.3 we present our results for different multidimensional affluence measures using different values of the second cutoff threshold $k$ as well as different values of $\alpha$ and $\beta$ respectively. Analogous to the one-dimensional case, the dimension adjusted headcount ratio $\left(R_{H R}^{M}\right)$ is equal to 0.2 for $k=1$ due to the choice of cutoffs. However, this is not necessarily the case for $k=2$, where we find a larger value for the US (0.11) compared to Germany (0.08). This means that the relative number of total affluence counts is larger in the US. Turning to the convex multidimensional affluence measures $\left(R_{\alpha}^{M}\right)$ we find that for both levels of the second cutoff $(k=1$ and $k=2)$ the levels are much higher in the US. Whereas the difference for $\alpha=1$ is comparably moderate it turns out to 
be huge for $\alpha=2$, which implies a strong emphasis of the very top. This implies that affluence in the US is much more concentrated at the very top of the joint distribution of income and wealth, consisting of only few households and individuals. However, looking at the concave measures $\left(R_{\beta}^{M}\right)$ we find (slightly) higher levels of multidimensional affluence for Germany, in particular for $k=1$, which results from the weaker (rank) correlation between dimensions. This indicates that affluence in Germany is more equally distributed among a larger number of households and individuals not differing too much in their income and wealth levels, whereas in the US extreme affluence results from a smaller group of affluent units where some exhibit extreme income and wealth levels.

Contributions. As we pointed out before, another advantage of our measures of multidimensional affluence is that they allow to quantify the contribution of each dimension to the overall level of affluence. Figure B.4 displays the percentage contribution of income and wealth respectively. We find that in both countries the relative importance of both dimensions is quite balanced for all measures (with income having a slightly greater contribution in Germany compared to the US). The only exception is the convex measure for $\alpha=2$. For this, the two countries differ substantially. The contribution of income is reduced to $20-30 \%$ in Germany depending on the second cutoff level $k$, whereas it amounts to around $60 \%$ in the US. This means that the composition of affluence at the very top differs a lot between the US and Germany, whereas income and wealth seem to contribute more or less evenly when extreme affluence is less emphasized.

United States 1989-2007. We now turn an assessment of the development of multidimensional affluence over time in the US during the period from 1989 to 2007.18 We compare our results to an updated time series of top income shares in the US (Piketty and Saez, 2003, 2007) provided by Alvaredo et al. (2011). Figure B.5 depicts shares of the top $10 \%$ to top $0.01 \%$ incomes including capital gains since this comes closest to our joint consideration of income and wealth. The share of

\footnotetext{
18 Unfortunately, it is not possible to extend the analysis over time to the German case since the SOEP is the only data source for Germany with sufficient information on wealth, which is available only for two waves.
} 
the very top of the income distribution in the US has been increasing steadily since the mid-1990s with the exception of a short recession period at the beginning of the 2000s following the burst of the dot-com bubble. In Figure B.6 we present the development of mean and median income and wealth for the total population as well as for the three subgroups according to the age of the household head. Overall, the mean values of both dimensions under consideration show stronger growth rates than the median values ${ }^{19}$ This is especially true for the oldest age groups, while income and wealth levels for the youngest group have remained more or less constant throughout the period under consideration.

In the previous section we reported that the US and Germany clearly differ in the association between rank positions within the income and wealth distributions for 2007 data. We find that this correlation is much stronger in the US compared to Germany. Figure B.7 shows the development of the rank correlation between 1989 and 2007. Throughout the whole period, it holds that the correlation has been stronger than it was in Germany in 2007 we find that there has been a considerable increase in the US since the beginning of the 1990s. For the whole population, the Spearman index grew from below 0.5 to a level of around 0.6. This growth turns out to be even stronger for the subpopulation with at least one affluence count (increase from 0.35 to 0.55 ) and also increased somewhat for the multidimensionally affluent population (increase from 0.65 to $0.75-0.8$ ). Hence, the high-income individuals more often also exhibit the highest levels of wealth. This should clearly contribute to an increasing level of affluence in both dimensions.

Figures $\mathrm{B} .9 \mathrm{a}$ and $\mathrm{B.9} \mathrm{b}$ depict the development of one-dimensional affluence for income and wealth respectively. For both we find that affluence measured by the concave indices $\left(R_{\beta}\right)$ remained remarkably unchanged throughout the period 19892007 and shows almost no volatility at all. This is contrasted by the convex measures $\left(R_{\alpha}\right)$ putting more weight on the extreme top of the respective distributions: For income, the convex measures increased strongly since the beginning of the 2000s after having remained constant throughout the 1990s (no statistically significant changes) with the exception of a dip in 1992 due to the contraction of the US

\footnotetext{
${ }^{19}$ Figure B.8 depicts the development of selected inequality measures which show a clear upward trend throughout the period.
} 
economy. Convex affluence in wealth did not significantly change throughout the first four waves (1989-1998) despite a clear increasing pattern of point estimates. The convex measures for $\alpha=2$ dropped significantly to lower levels in 2001 and 2004 before increasing again between the 2004 and 2007 waves.

We present our results for multidimensional affluence in the US between 1989 and 2007 in Figures B.10a and B.10b for the two possible levels of second stage cutoffs. The measures only differ in levels for $k=1$ or $k=2$ but the trend patterns over time are very similar: Relying on the concave measures yields that multidimensional affluence has remained almost constant throughout the period 1989-2007, whereas the convex measures exhibit some volatility. We find a statistically significant drop of convex measures between 1989 and 1992 for both values of $\alpha$ due to the contraction at that time. For $\alpha=1$, multidimensional affluence afterwards remained constant between 1995 and 2004 and increased between 2004 and 2007. Hence, this measure remained unaffected by the recession in 2000/2001 while we find a significant drop of affluence measured with $\alpha=2$, which implies strongly emphasizing very high achievements in both income and wealth. This means, the dot-com crisis particularly affected the very top of the distribution of economic well-being in the US, which is mainly due to its impact on wealth holdings. Although large confidence intervals (based on bootstrapping) indicate a fair amount of imprecision in estimated levels of affluence we find a very strong increase between 2004 and 2007. In fact, we observe a doubling of point estimates. Hence, in the first half of the 2000s, the top of the joint distribution of income and wealth not only recovered from its losses at the beginning of the decade but even increased their economic resources to a historically high level. However, since the available SCF data do not cover the recent crisis, it can be assumed that the Great Recession has reversed this trend sharply ${ }^{20}$

\subsection{Robustness checks}

Different cutoffs. We calculated the multidimensional affluence indices for different levels of the dimension-specific cutoffs, i.e. higher percentiles of the marginal

20 The 2009 SCF panel survey reinterviewed participants from the 2007 cross-sectional survey in order to capture the impact of the crisis on private finances. However, this data is not (yet) available for public use (see Bricker et al., 2011). 
distributions of income and wealth. As for our baseline specification, we defined the cutoffs separately by age of the household head. The results are presented in Figure B.11. The levels of the indices vary by the level of cutoff with smaller values for higher quantiles. However, the patterns we found for the baseline cutoff (80\%-quantile of the age-specific distributions) are pretty similar. In particular, the cross-country differences remain almost unchanged, except for the concave measures. Whereas in our baseline results Germany exhibits (slightly) larger levels for this set of indices, they are almost the same for both countries or slightly larger in the US.

Weighting of dimensions. In both our theoretical consideration as well as in our empirical application of multidimensional affluence measurement we did not consider the issue of weighting dimensions and implicitly applied equal weights to both dimensions under consideration. Equal weighting is popular for its simplicity and its easy interpretation. Furthermore, it is the most appropriate choice if all dimensions are indeed equally important for economic well-being Atkinson, 2003 . Alkire and Foster, 2011a). Decancq and Lugo (2011b), however, argue that the weighting scheme determines the trade-off structure among dimensions and is crucial for choosing the dimensions since not considering several potential dimensions implicitly means assigning a weight of zero to them. Hence, any choice of weighting scheme clearly has normative implications (Decancq et al., 2009; Decancq and Ooghe, 2010). However, although equal weighting is not uncontroversial in the literature on multidimensional well-being there is also no agreement on a specific weighting scheme among various possible choices (see Decancq and Lugo, 2011b, for an overview). Rather than making a specific alternative choice we present results for a range of possible combinations of different weights. ${ }^{21}$ We distinguish between Germany and the US as well as the cases of a union, an intermediate and an intersection approach to the dual cutoff method (see Alkire and Foster, 2011a, p. 479-480). The union approach represents one extreme case where an individual is identified as multidimensionally affluent as soon as the sum of weighted counts is not below the least weight given to one of the dimensions under consideration. The other ex-

${ }^{21}$ See Appendix C for a more general representation of the multidimensional measures for different weights. 
treme approach, the intersection case, by contrast requires that the sum of weighted counts is equal to the total sum of weights. In our application using two dimensions and equal weights these cases were represented by the cutoffs $k=1$ (union) and $k=2$ (intersection) respectively. Allowing for different weights (and/or expanding the number of dimensions) allows intermediate cases, where an individual is affluent when its weighted counts are below the total sum of weights but are larger than the least weight. In Figure C.13 we plot the values of the multidimensional affluence indices against the weight of income, while Figure C.14 shows the contribution of this dimension for different weights. Overall the results for the multidimensional affluence indices are not very sensitive to the weighting scheme. There is only some noise for the intermediate case. Moreover, the relationship between the relative weight of a dimension and its contribution to overall affluence is almost described by a linear function with the exception of the convex measure for $\alpha=2$. For the German data, the contribution of income only grows slowly (the curve lies below the 45-degree line) while it increases rapidly in the US. This confirms our result that income and wealth contribute differently to multidimensional affluence when emphasizing the very top of the distributions.

\section{Discussion}

Data quality: administrative vs. survey data. Kopczuk and Saez (2004) discuss different reasons for discrepancies in findings between studies based on survey data and administrative tax return data. These are related to different concepts of income or wealth and to tax avoidance and evasion. The literature on top incomes typically makes use of administrative data from tax records. Piketty (2005) argues that, in contrast to other (survey) data sources, these data are homogeneous over time, comparable across country and decomposable with respect to income sources. Furthermore, administrative data do not suffer from non-response, especially regarding the top of the distribution.

Since, unfortunately, administrative data are not available to us (in case of the US) or only for a very restricted period (in case of Germany) we have to rely 
on survey data. Although these data indeed do not cover a long time span, we argue that they are nevertheless useful for our purposes since we are not primarily interested in the historical development of multidimensional affluence. First, the SOEP as well as the SCF surveys provide harmonized information on income and wealth over time and allow a restriction to specific income components (see above). Second, both surveys are explicitly concerned with representativeness of top incomes and wealth holdings by specific sampling procedures. Finally, as elaborated in Alkire and Foster (2011b), our methodology requires income and wealth information from the same data source, which must be linked on the individual (or household) level in order to be able to assess the joint distribution. Tax return data typically do not provide both types of information simultaneously. Furthermore, they do not contain information on non-taxable income sources (e.g. owner-occupied housing or private life insurance in Germany). In addition, while survey data are subject to measurement error, tax data suffer from underreporting due to tax evasion, which is particularly severe at the top (Kopczuk and Saez, 2004; Paulus, 2011).

We check whether utilizing administrative data from tax records yields approximately similar results to survey data. We use German tax data (FAST ${ }^{22}$ ), which is a $10 \%$ stratified random sample from all German income tax records - about 3 million cases - available for scientific use. The FAST data provide detailed information on various aspects that are relevant for income taxation on the micro level (individuals and married couples). We use data from 2001 since this allows a comparison with the SOEP wave 2002 which comprise income and wealth information for the previous calender year.23

We define income as the sum of all market income subject to income taxes less income from capital (dividends) and construct a proxy for wealth holdings as the level of income from capital divided by an interest rate of around 7\%, which we calculated from the SOEP (average sum of capital gains over the sum of business

${ }^{22}$ FAST-Faktisch anonymisierten Daten aus der Lohn- und Einkommensteuerstatistik, see http: //www.forschungsdatenzentrum.de/bestand/lest/suf/2001/index.asp (in German).

23 The FAST data are available for 1998, 2001 and 2004; the SOEP data with wealth information for 2001 and 2006. Unfortunately, administrative tax data for the US are not available to us. Although tax record data have several advantages over survey data (esp. reliability of income information and representativeness) they do not contain direct information on wealth holdings. 
assets). Unfortunately, the tax data does not comprise proxies for property wealth, since especially owner-occupied housing is not subject to income taxation. Hence, income from capital gains is an incomplete proxy for wealth since owner-occupied housing does not yield directly measurable income streams (only via imputed rents for owner-occupiers, see e.g. Smeeding and Thompson, 2011). This poses a "serious challenge" for this capitalization of income method (cf. Kopczuk and Saez, 2004). Hence, we also do not consider this in the SOEP data for this comparative exercise. In addition, the (sample) populations of both data sources are not comparable. While the SOEP is designed to representatively cover the whole population, the FAST data only comprise tax payers, i.e. a specific subpopulation. In particular, pensioners are less likely to pay income taxes as in 2001 in Germany only a small share of public pension income was subject to taxation. That is why we use only one cutoff for the whole sample at the 99\%-quantile since up to this level the SOEP data compare very well to the tax data (Bach et al. 2009). Table A.4 presents the results, which are almost identical for the multidimensional headcount ratio as well as for the concave measures. Only for the convex indices, which put more weight on the very top, affluence measures based on tax data are unsurprisingly higher.

Standard errors. As we are restricted to rather small samples for our empirical analysis, an issue arising is the precision of estimated values of multidimensional affluence indices. This is particularly true for the convex measures, which are more sensitive to extreme values at the top of the income and wealth distributions. As noted above, we apply the bootstrap method in order to derive empirical standard errors and find that the more emphasis is put on the very top the more imprecise the point estimates become. In particular, when analyzing the trend of (multidimensional) affluence over the 1989-2007 period in the US it is not always possible to detect statistically significant changes in affluence levels over time although point estimates show clear trends (see Figures B.9 and B.10). Hence, there is a sort of trade-off between precision in estimation and emphasizing very intense affluence at least in the case of the convex measures. 
Pension wealth. An important motive for building a wealth stock over the life cycle is precautionary saving, not only in order to smooth consumption over income shocks but in particular also as a form of old-age provision. The importance of private savings to secure a certain standard of living after retiring depends on the institutional setting (in particular the public pension system). While in Germany the most important pillar of the pension system relies on a statutory and compulsory pay-as-you-go pension scheme for dependent employees (and hence for a majority of the workforce), the system of publicly organized old-age provision in the US is much less important for the individual retiree. As a consequence, private old-age provision - in form of housing, stocks, bonds or pension funds - is much more important. Although the present values of future pension entitlements from a statutory pension scheme are not marketable (i.e. they cannot be sold or lend against) they nevertheless can be viewed as a special form of wealth since they represent a substitute for private old-age provision. Hence, the standard definition of net wealth described above does not take into account an important component of an individual's wealth portfolio ${ }^{24}$ What follows from this line of argument is that it is desirable to include a measure of "pension wealth" when comparing countries with distinct pension systems (Frick and Heady, 2009). As an illustration, we use cell means for public pension entitlements and merge them to the SOEP data. ${ }^{25}$ Consistent with previous findings (Rasner et al., 2011), incorporating pension wealth has a strong equalizing effect, in particular at the very top (see Figure B.12).

Other dimensions. We restrict our empirical illustration to income and wealth as dimensions of multidimensional affluence since these can be considered as core indicators of economic well-being. However, one can think of going beyond monetary measures of well-being and extend the analysis to measures of leisure, health or life satisfaction in general. Feasibility however depends on available data sources which comprise information on all dimensions of interest.

\footnotetext{
24 Comparing Germany and Australia, Frick and Heady (2009) show that neglecting social security wealth can yield misleading results in cross-country comparison.

${ }^{25}$ We thank Markus M. Grabka (DIW Berlin) for providing us with the information used in Rasner et al. (2011) for different groups by age, gender, occupational status and region.
} 


\section{Conclusions}

In this paper, we propose measures for multidimensional affluence. We argue that the analysis of economic well-being, and especially the top of its distribution, should not only consider income as a single dimension, but in addition take into account further dimensions in order to provide a differentiated picture of economic wellbeing. We distinguish convex and concave measures of affluence, where the first put more emphasis on inequality at the very top of the joint distribution.

Using micro data from the SOEP and the SCF, we apply this framework to Germany and the United States (in 2007) and perform a cross-country analysis as well as an analysis of multidimensional affluence over time in the US (1989-2007). Conclusions derived from our results depend on the choice of multidimensional measure of affluence. It turns out, that according to the concave measures the German population is overall slightly more affluent than the US population and multidimensional affluence has remained constant during a period of nearly two decades. However, when referring to the convex measurement of multidimensional affluence, the US clearly outperforms Germany and there is volatility in affluence in the US between 1989 and 2007. In particular, based on a measure putting most emphasis on extreme affluence, we find that the very top of the joint distribution of income and wealth was responsible for most of volatility in inequality at the top. This is not only true during times of recession but also for a more recent period, when the US experienced a strong surge in multidimensional affluence.

Moreover, our approach allows to quantify the relative importance of single dimensions contributing to multidimensional affluence. We find that, in general, both income and wealth are equally important. Only when emphasizing extreme affluence there is a clear difference between the two countries: While in Germany wealth predominantly contributes to intense affluence in a multidimensional setting,

income is more important in the US. Note again that our empirical application is based on survey data. Future research could employ administrative data in order to analyze several dimensions with different weights. 


\section{References}

Alkire, S. and J. Foster (2011a). Counting and Multidimensional Poverty Measurement. Journal of Public Economics 95(7-8), 476-487.

Alkire, S. and J. Foster (2011b). Understandings and Misunderstandings of Multidimensional Poverty Measurement. Journal of Economic Inequality 9(2), 289-314.

Alvaredo, F., A. B. Atkinson, T. Piketty, and E. Saez (2011). The World Top Incomes Database. http://g-mond.parisschoolofeconomics.eu/topincomes, $30 / 05 / 2011$.

Atkinson, A. B. (2003). Multidimensional Deprivation: Contrasting Social Welfare and Counting Approaches. Journal of Economic Inequality 1(1), 51-65.

Atkinson, A. B. (2005). Comparing the Distribution of Top Incomes Across Countries. Journal of the European Economic Association 3(2-3), 393-401.

Atkinson, A. B. (2007). Measuring Top Incomes: Methodological Issues. In A. B. Atkinson and T. Piketty (Eds.), Top Incomes over the Twentieth Century, Chapter 2, pp. 18-42. Oxford: Oxford University Press.

Atkinson, A. B. (2008). Concentration among the Rich. In J. B. Davies (Ed.), Personal Wealth from a Global Perspective. Oxford University Press, Oxford.

Atkinson, A. B. and A. Brandolini (2011). On the Identification of the "Middle Class". In J. C. Gornick and M. Jäntti (Eds.), Inequality and the Status of the Middle Class. Stanford University Press, Stanford, forthcoming.

Atkinson, A. B. and T. Piketty (2007). Top Incomes over the Twentieth Century. Oxford: Oxford University Press.

Atkinson, A. B., T. Piketty, and E. Saez (2011). Top Incomes in the Long Run of History. Journal of Economic Literature 49(1), 3-71.

Bach, S., G. Corneo, and V. Steiner (2009, June). From Bottom to Top: The Entire Income Distribution in Germany, 1992-2003. Review of Income and Wealth 55(2), 303-330.

Bourguignon, F. and S. R. Chakravarty (2003). The Measurement of Multidimensional Poverty. Journal of Economic Inequality 1(1), 25-49.

Bricker, J., B. K. Bucks, A. B. Kennickell, T. L. Mach, and K. B. Moore (2011). Surveying the Aftermath of the Storm: Changes in Family Finances from 2007 to 2009. Finance and Economics Discussion Series No. 2011-17.

Bucks, B. K., A. B. Kennickell, T. L. Mach, and K. B. Moore (2009). Changes in U.S. Family Finances from 2004 to 2007: Evidence from the Survey of Consumer Finances. Federal Reserve Bulletin, A1-A56.

Burkhauser, R., S. Feng, S. Jenkins, and J. Larrimore (2011a). Recent Trends in Top Income Shares in the USA: Reconciling Estimates from March CPS and IRS Tax Return Data. Review of Economics and Statistics forthcoming. 
Burkhauser, R., S. Feng, S. Jenkins, and J. Larrimore (2011b). Trends in United States Income Inequality Using the March Current Population Survey: The Importance of Controlling for Censoring. Journal of Economic Inequality forthcoming.

Cowell, F. A. (2008). Measuring Inequality. Oxford: Oxford University Press.

Cowell, F. A. (2011). Inequality among the Wealthy. CASE Papers No. 150.

D'Ambrosio, C., J. R. Frick, and M. Jäntti (2009). Satisfaction with Life and Economic Well-Being: Evidence from Germany. Schmollers Jahrbuch - Journal of Applied Social Sciences 129(2), 283-295.

Davies, J. B., S. Sandström, A. B. Shorrocks, and E. N. Wolff (2009, November). The Level and Distribution of Global Household Wealth. NBER Working Paper No. 15508.

Decancq, K., A. Decoster, and E. Schokkaert (2009). The Evolution of World Inequality in Well-Being. World Development 37(1), 11-25.

Decancq, K. and M. A. Lugo (2011a). Inequality of Well-Being: A Multidimensional Approach. Economica forthcoming.

Decancq, K. and M. A. Lugo (2011b). Weights in Multidimensional Well-Being: An Overview. Econometric Reviews forthcoming.

Decancq, K. and E. Ooghe (2010). Has the World Moved Forward? A Robust Multidimensional Evaluation. Economics Letters 107(2), 266-269.

Dell, F. (2005). Top Incomes in Germany and Switzerland over the Twentieth Century. Journal of the European Economic Association 3(2-3), 412-421.

Edlund, L. and W. Kopczuk (2009). Women, Wealth, and Mobility. American Economic Review 99(1), 146-178.

Eisenhauer, J. G. (2011). The Rich, the Poor, and the Middle Class: Thresholds and Intensity Indices. Research in Economics forthcoming.

Foster, J., J. Greer, and E. Thorbecke (1984). A Class of Decomposable Poverty Measures. Econometrica 52(3), 761-766.

Frank, R. L. (2007). Richistan: A Journey Through the American Wealth Boom and the Lives of the New Rich. New York: Random House.

Frick, J. R., J. Goebel, M. M. Grabka, O. Groh-Samberg, and G. G. Wagner (2007). Zur Erfassung von Einkommen und Vermögen in Haushaltssurveys: Hocheinkommensstichprobe und Vermögensbilanz im SOEP. SOEPpaper on Multidisciplinary Panel Data Research No. 19.

Frick, J. R. and M. M. Grabka (2009). Wealth Inequality on the Rise in Germany. DIW Weekly Report 5(10), 62-73. 
Frick, J. R., M. M. Grabka, and J. Marcus (2007). Editing and Multiple Imputation of Item-Non-Response in the 2002 Wealth Module of the German Socio-Economic Panel (SOEP). SOEPpaper on Multidisciplinary Panel Data Research No. 18.

Frick, J. R. and B. Heady (2009). Living Standards in Retirement: Accepted International Comparisons are Misleading. Schmollers Jahrbuch - Journal of Applied Social Sciences 129(2), 309-319.

Fuchs-Schündeln, N., D. Krüger, and M. Sommer (2010). Inequality Trends for Germany in the Last Two Decades: A Tale of Two Countries. Review of Economic Dynamics 13(1), 103-132.

Grabka, M. M. (2007). Codebook for the PEQUIV File 1984-2006. CNEF Variables with Extended Income Information for the SOEP. Data Documentation 21, DIW Berlin.

Heathcote, J., F. Perri, and G. Violante (2010). Unequal We Stand: An Empirical Analysis of Economic Inequality in the United States, 1967-2006. Review of Economic Dynamics 13(1), 15-51.

Jenkins, S. P. and M. Jäntti (2005). Methods for Summarizing and Comparing Wealth Distributions. ISER Working Paper No. 2005-05.

Jäntti, M., E. Sierminska, and T. M. Smeeding (2008). The Joint Distribution of Household Income and Wealth: Evidence from the Luxembourg Wealth Study. OECD Social, Employment and Migration Working Paper No. 65, Paris.

Kennickell, A. B. (2009). Ponds and Streams: Wealth and Income in the U.S., 1989 to 2007. Finance and Economics Discussion Series No. 2009-13.

Kopczuk, W. and E. Saez (2004). Top Wealth Shares in the United States, 19162000: Evidence from Estate Tax Returns. National Tax Journal 57(2), 445-487.

Michelangeli, A., E. Peluso, and A. Trannoy (2011). Detecting a Change in Wealth Concentration without the Knowledge of the Wealth Distribution. Journal of Economic Inequality forthcoming.

OECD (2008). Growing Unequal? Income Distribution and Poverty in OECD Countries. Organisation for Economic Co-Operation and Development, Paris.

Paulus, A. (2011). Tax Evasion and Measurement Error: A Comparison of Survey Income with Tax Records. mimeo, University of Essex.

Peichl, A., T. Schaefer, and C. Scheicher (2010). Measuring Richness and Poverty: A Micro Data Application to Europe and Germany. Review of Income and Wealth 56(3), 597-619.

Piketty, T. (2005). Top Income Shares in the Long Run: An Overview. Journal of the European Economic Association 3(2-3), 382-392.

Piketty, T. (2011). On the Long-Run Evolution of Inheritance: France 1820-2050. Quarterly Journal of Economics forthcoming. 
Piketty, T. and E. Saez (2003). Income Inequality in the United States, 1913-1998. Quarterly Journal of Economics 118(1), 1-39.

Piketty, T. and E. Saez (2006). The Evolution of Top Incomes: A Historical and International Perspective. American Economic Review, Papers and Proceedings 96(2), 200-205.

Piketty, T. and E. Saez (2007). Income and Wage Inequality in the United States 1913-2002. In A. Atkinson and T. Piketty (Eds.), Top Incomes over the Twentieth Century, Chapter 5, pp. 141-225. Oxford: Oxford University Press.

Rasner, A., J. R. Frick, and M. M. Grabka (2011). Extending the Empirical Basis for Wealth Inequality Research Using Statistical Matching of Administrative and Survey Data. SOEPpapers on Multidisciplinary Panel Data Research No. 359.

Roine, J., J. Vlachos, and D. Waldenström (2009). The Long-Run Determinants of Inequality: What Can We Learn from Top Income Data? Journal of Public Economics 93(7-8), 974-988.

Roine, J. and D. Waldenström (2008). The Evolution of Top Incomes in an Egalitarian Society: Sweden, 1903-2004. Journal of Public Economics 92(1-2), 366-387.

Roine, J. and D. Waldenström (2009). Wealth Concentration over the Path of Development: Sweden, 1873-2006. Scandinavian Journal of Economics 111(1), 151-187.

Roine, J. and D. Waldenström (2011). Common Trends and Shocks to Top Incomes - A Structural Breaks Approach. Review of Economics and Statistics forthcoming.

Saez, E. (2005). Top Incomes in the United States and Canada over the Twentieth Century. Journal of the European Economic Association 3(2-3), 402-411.

Saez, E. and M. Veall (2005). The Evolution of High Incomes in Northern America: Lessons from Canadian Evidence. American Economic Review 95(3), 831-849.

Smeeding, T. M. and J. P. Thompson (2011). Recent Trends in Income Inequality: Labor, Wealth and More Complete Measures of Income. Research in Labor Economics 32, 1-50.

Socio-Economic Panel (2010). Data for Years 1984-2009, Version 26. SOEP.

Stiglitz, J. E., A. Sen, and J.-P. Fitoussi (2009). Report by the Commission on the Measurement of Economic Performance and Social Progress. Paris.

Wagner, G. G., J. R. Frick, and J. Schupp (2007). The German Socio-Economic Panel Study (SOEP) - Scope, Evolution and Enhancements. Schmollers Jahrbuch - Journal of Applied Social Sciences 127(1), 139-169.

Waldenström, D. (2009). Lifting All Boats? The Evolution of Income and Wealth Inequality over the Path of Development. Lund Studies in Economic History 51.

Wolff, E. N. and A. Zacharias (2009). Household Wealth and the Measurement of Economic Well-Being in the United States. Journal of Economic Inequality 7(2), $83-115$. 


\section{Appendix}

\section{A Tables}

Table A.1: Descriptives and cutoffs

\begin{tabular}{lccccc}
\hline \hline & Mean & Median & Cutoff $<30$ & Cutoff 30-59 & Cutoff 60+ \\
\hline \hline United States 2007 & & & & & \\
\hline Income & 44,982 & 27,252 & 37,021 & 63,245 & 36,358 \\
& $(434)$ & $(358)$ & $(1,022)$ & $(715)$ & $(1,269)$ \\
Wealth & 355,984 & 70,750 & 35,921 & 280,050 & 590,399 \\
& $(4,741)$ & $(1,860)$ & $(4,878)$ & $(7,219)$ & $(16,899)$ \\
\hline Germany 2007 & & & & & \\
\hline Income & 25,415 & 21,670 & 33,784 & 50,290 & 17,732 \\
& $(336)$ & $(455)$ & $(1,681)$ & $(640)$ & $(1,281)$ \\
Wealth & 134,300 & 43,873 & 26,942 & 173,145 & 259,284 \\
& $(4,289)$ & $(2,193)$ & $(3,090)$ & $(4,600)$ & $(7,228)$ \\
\hline \hline
\end{tabular}

Note: Income and wealth in PPP US Dollars. Confidence intervals (95\%) based on 500 bootstrap replications. Source: $\mathrm{SCF} / \mathrm{SOEP}$, own calculations.

Table A.2: One-dimensional Measures

\begin{tabular}{lcccccc}
\hline \hline & $R_{H R}$ & $R_{\alpha=1}$ & $R_{\alpha=2}$ & $R_{\beta=1}$ & $R_{\beta=3}$ & $I_{\text {Gini }}$ \\
\hline \hline United States 2007 & & & & & & \\
\hline Income & 0.199 & 0.110 & 10.492 & 0.019 & 0.030 & 0.561 \\
& $(0.000)$ & $(0.005)$ & $(2.074)$ & $(0.001)$ & $(0.001)$ & $(0.003)$ \\
Wealth & 0.200 & 0.156 & 7.794 & 0.021 & 0.030 & 0.798 \\
& $(0.000)$ & $(0.006)$ & $(0.555)$ & $(0.000)$ & $(0.001)$ & $(0.002)$ \\
\hline Germany 2007 & & & & & & \\
Income & 0.200 & 0.101 & 0.397 & 0.032 & 0.053 & 0.416 \\
& $(0.000)$ & $(0.010)$ & $(0.120)$ & $(0.002)$ & $(0.002)$ & $(0.005)$ \\
Wealth & 0.200 & 0.106 & 1.598 & 0.027 & 0.046 & 0.651 \\
& $(0.000)$ & $(0.012)$ & $(0.541)$ & $(0.001)$ & $(0.001)$ & $(0.010)$ \\
\hline \hline
\end{tabular}

Note: Confidence intervals (95\%) based on 500 bootstrap replications. Source: SCF/SOEP, own calculations. 
Table A.3: Multidimensional Measures

\begin{tabular}{lccccc}
\hline \hline$k$ & $R_{H R}^{M}$ & $R_{\alpha=1}^{M}$ & $R_{\alpha=2}^{M}$ & $R_{\beta=1}^{M}$ & $R_{\beta=3}^{M}$ \\
\hline \hline United States 2007 & & & & & \\
\hline 1 & 0.199 & 0.133 & 9.143 & 0.020 & 0.030 \\
& $(0.000)$ & $(0.004)$ & $(1.126)$ & $(0.000)$ & $(0.001)$ \\
2 & 0.111 & 0.103 & 8.446 & 0.012 & 0.016 \\
& $(0.002)$ & $(0.004)$ & $(1.113)$ & $(0.000)$ & $(0.000)$ \\
\hline Germany 2007 & & & & & \\
\hline 1 & 0.200 & 0.104 & 0.997 & 0.030 & 0.049 \\
& $(0.000)$ & $(0.008)$ & $(0.280)$ & $(0.001)$ & $(0.001)$ \\
2 & 0.081 & 0.051 & 0.457 & 0.013 & 0.020 \\
& $(0.003)$ & $(0.006)$ & $(0.137)$ & $(0.001)$ & $(0.001)$ \\
\hline \hline \multicolumn{2}{c}{ Note: Confidence intervals (95\%) based on 500 bootstrap replications. Source: SCF/SOEP, own calcu- } \\
lations.
\end{tabular}

Table A.4: Multidimensional Measures

\begin{tabular}{lccccc}
\hline \hline$k$ & $R_{H R}^{M}$ & $R_{\alpha=1}^{M}$ & $R_{\alpha=2}^{M}$ & $R_{\beta=1}^{M}$ & $R_{\beta=3}^{M}$ \\
\hline \hline Germany (adminstrative data) 2001 & & & & & \\
\hline 1 & 0.010 & 0.018 & 0.375 & 0.004 & 0.007 \\
2 & 0.001 & 0.004 & 0.050 & 0.001 & 0.001 \\
\hline Germany (survey data) 2001 & & & & & \\
\hline 1 & 0.010 & 0.007 & 0.041 & 0.003 & 0.005 \\
2 & 0.002 & 0.002 & 0.010 & 0.000 & 0.001 \\
\hline \hline
\end{tabular}




\section{B Graphs}
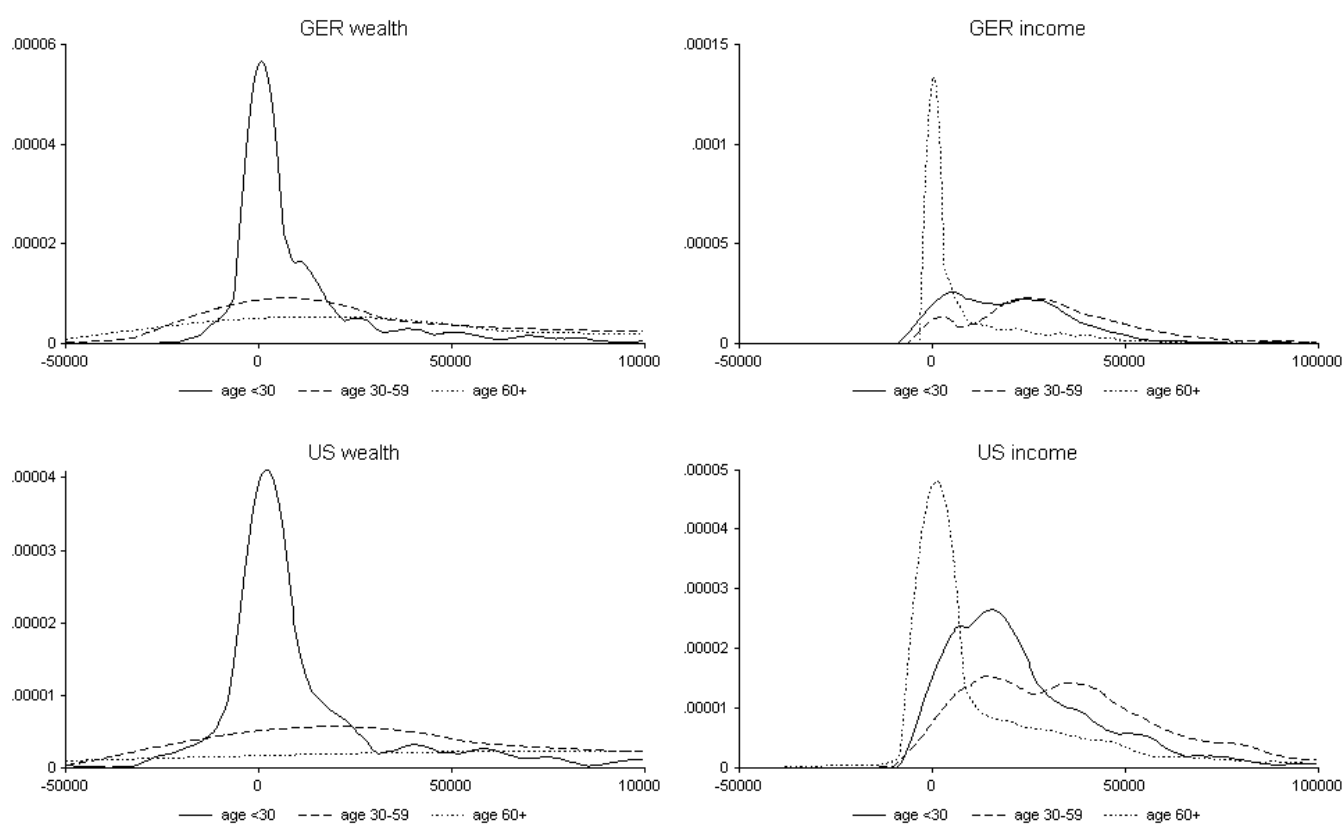

Source: SOEP/SCF, own calculations. Income and wealth in 2007 PPP-US Dollars.

Figure B.1: Income and wealth densities in Germany and the US (2007) by age of the household head 
Top income and wealth shares

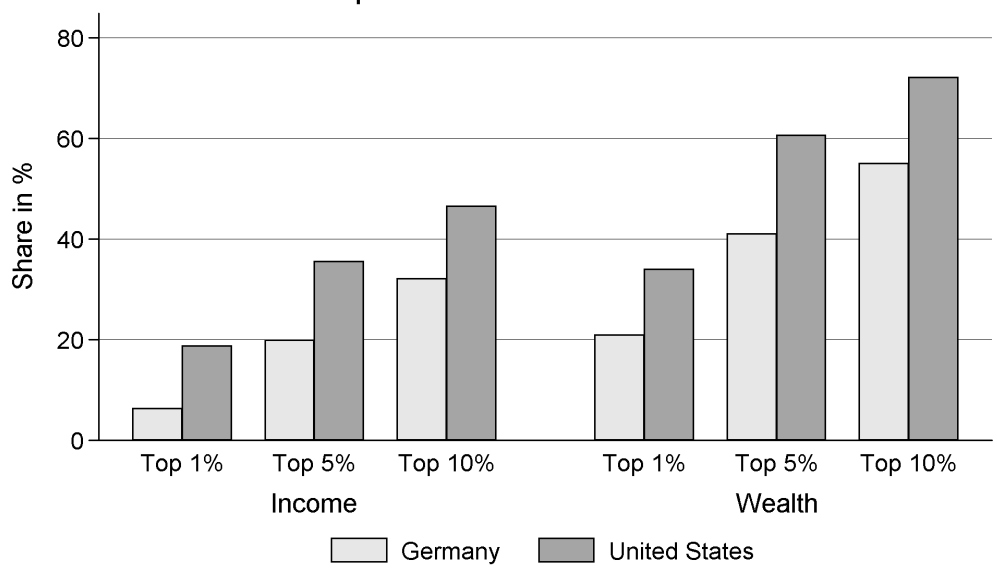

Source: SCF/SOEP, own calculations.

Income and wealth shares

for top fractiles in other dimension

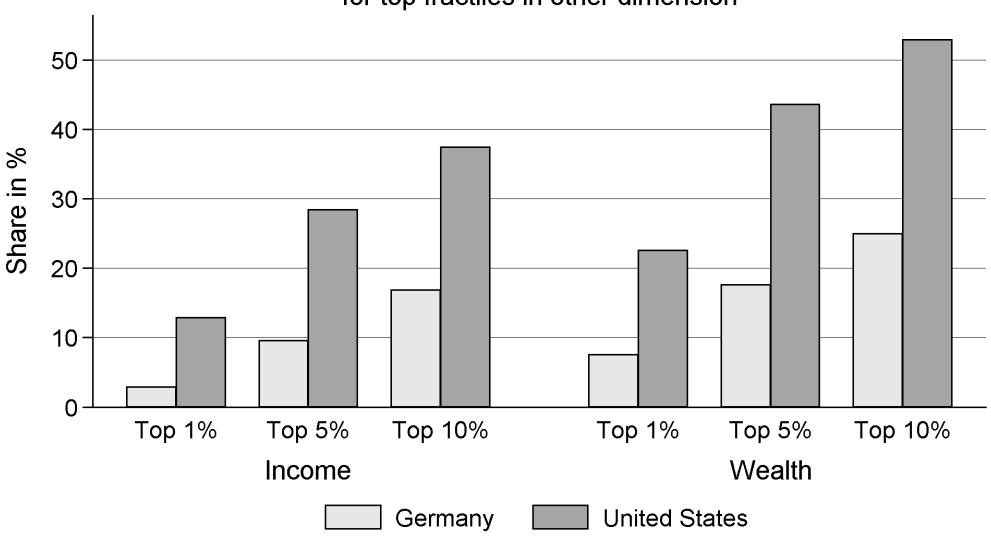

Source: SCF/SOEP, own calculations.

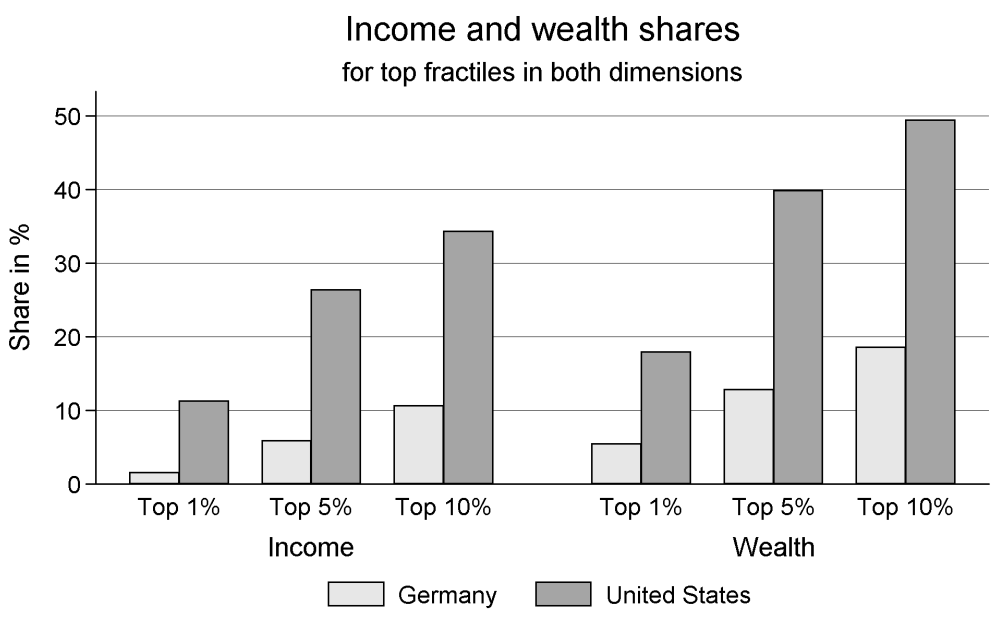

Source: SCF/SOEP, own calculations

Figure B.2: Income and wealth shares (2007) 


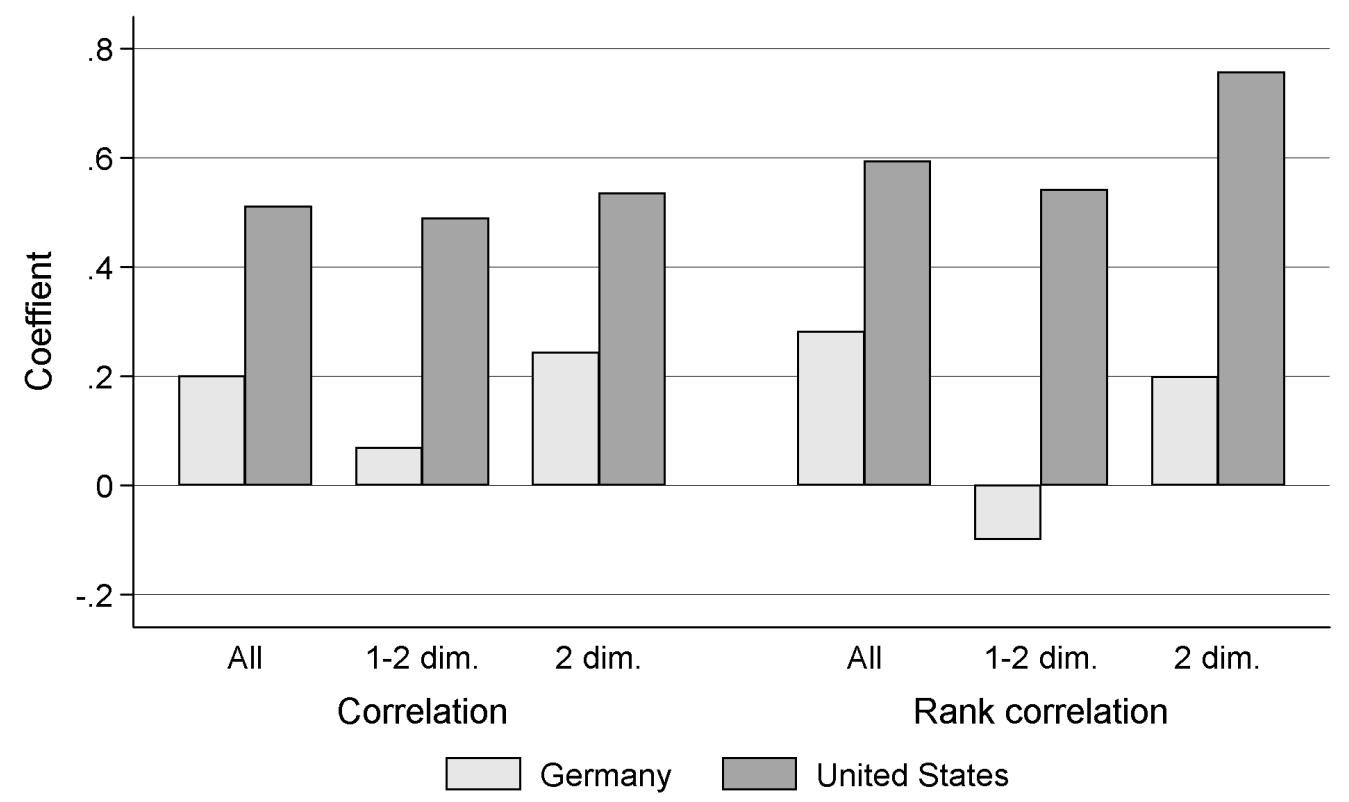

Source: SCF/SOEP, own calculations

All: affluent and non-affluent. 1-2 dim.: affluent in at least one dimension. 2 dim.: affluent in both dimensions.

Figure B.3: Correlations between income and wealth (2007) 

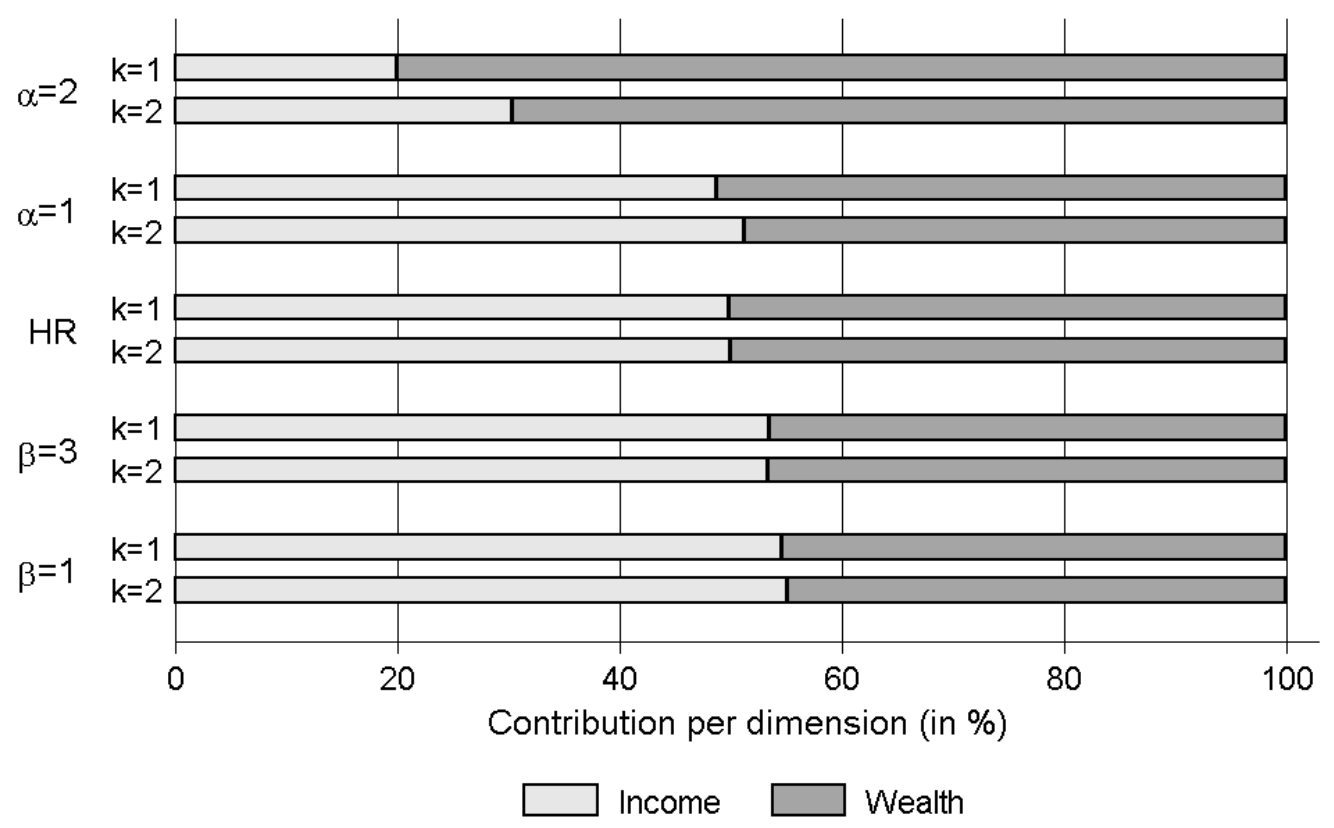

Source: SOEP 2007 , own calculations.

(a) Germany

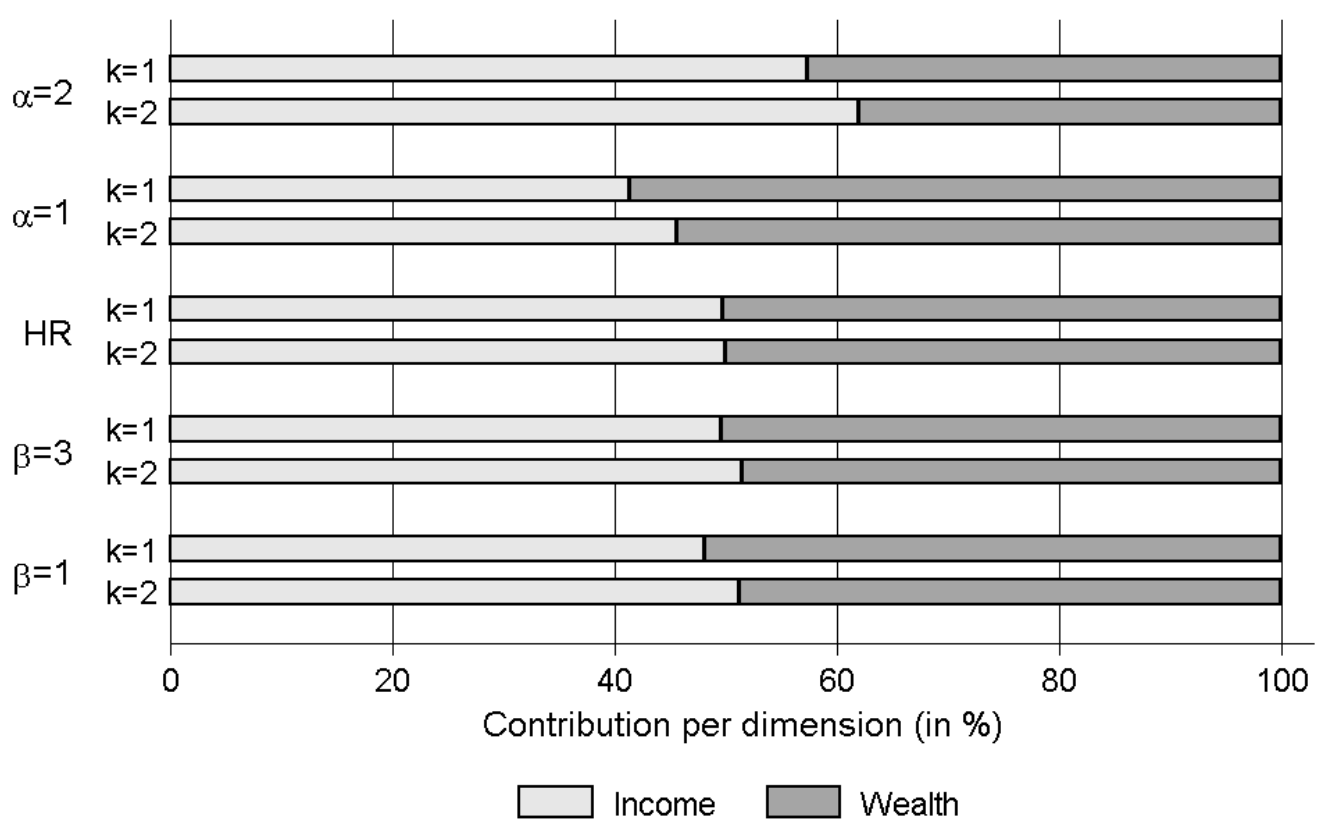

Source: SCF 2007 , own calculations.

(b) United States

Figure B.4: Affluence contributions per dimension (2007) 


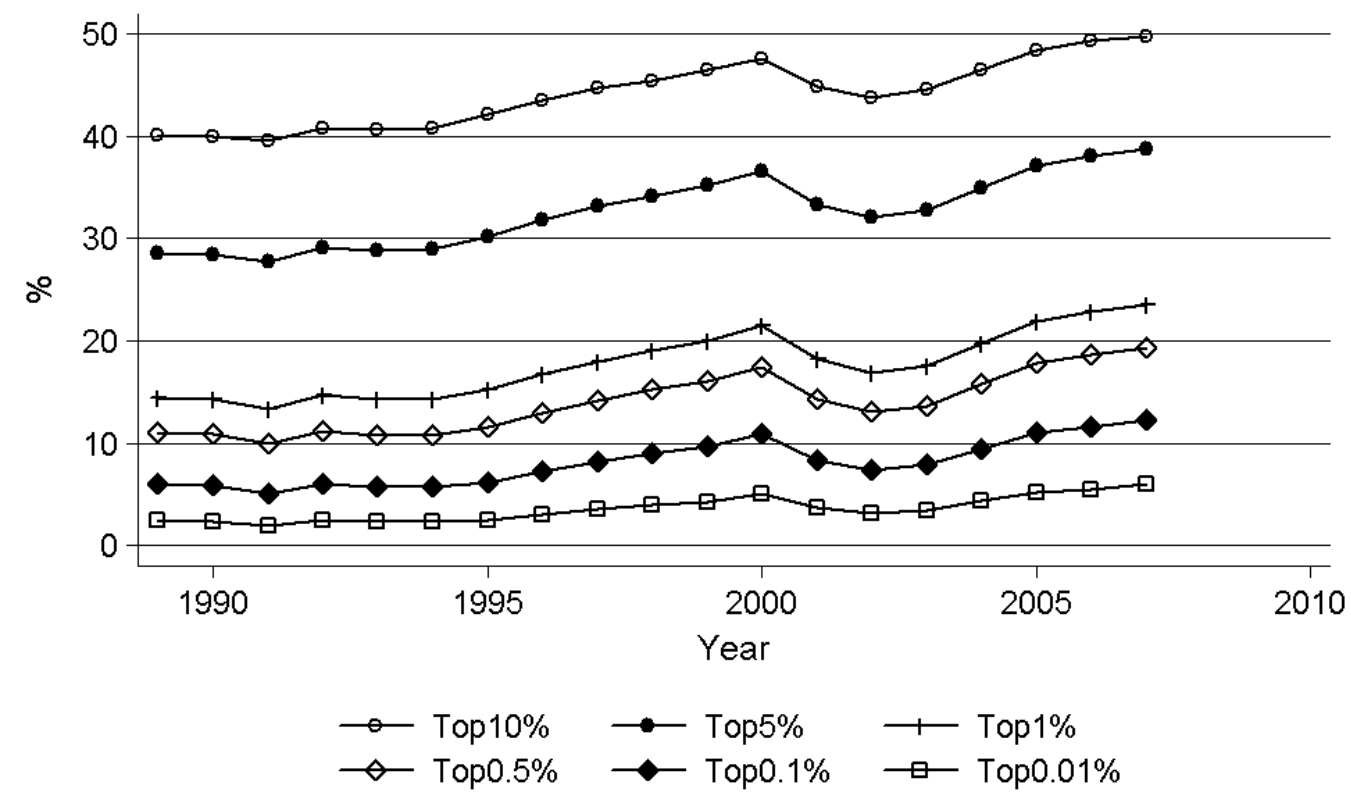

Source: Alvaredo, Facundo; Anthony B. Atkinson; Thomas Piketty and Emmanuel Saez: The World Top Incomes Database, http://g-mond.parisschoolofeconomics.eu/topincomes, 30/05/2011.

Figure B.5: Top income shares in the US (including capital gains)
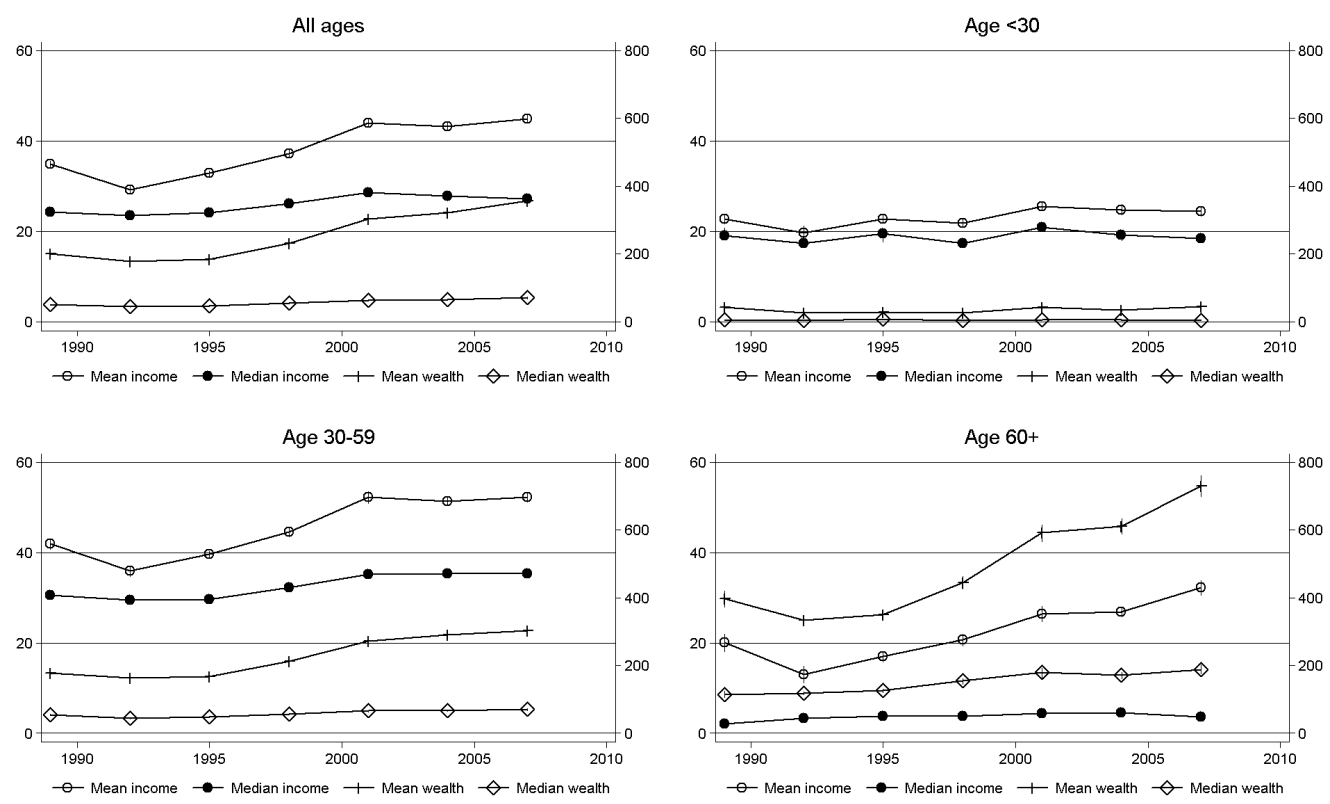

Source: SCF 1989-2007, own calculations. Income (left) and wealth (right) in 2007 USD divided by 1,000 Confidence intervals $(95 \%)$ based on 500 bootstrap replications.

Figure B.6: Income and wealth levels by age of the household head (US) 


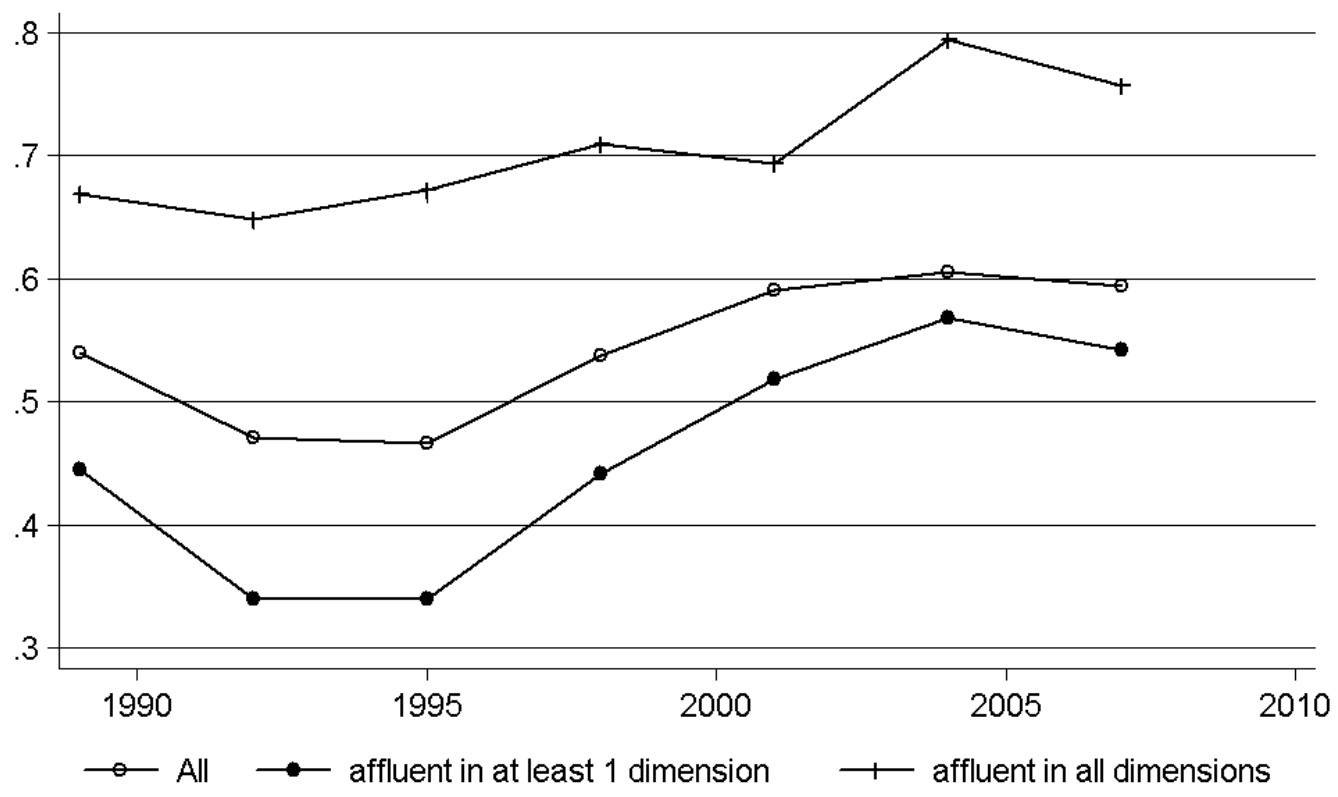

Source: SCF 1989-2007, own calculations.

Confidence intervals $(95 \%)$ based on 500 bootstrap replications.

Figure B.7: Rank correlation between income and wealth (US)

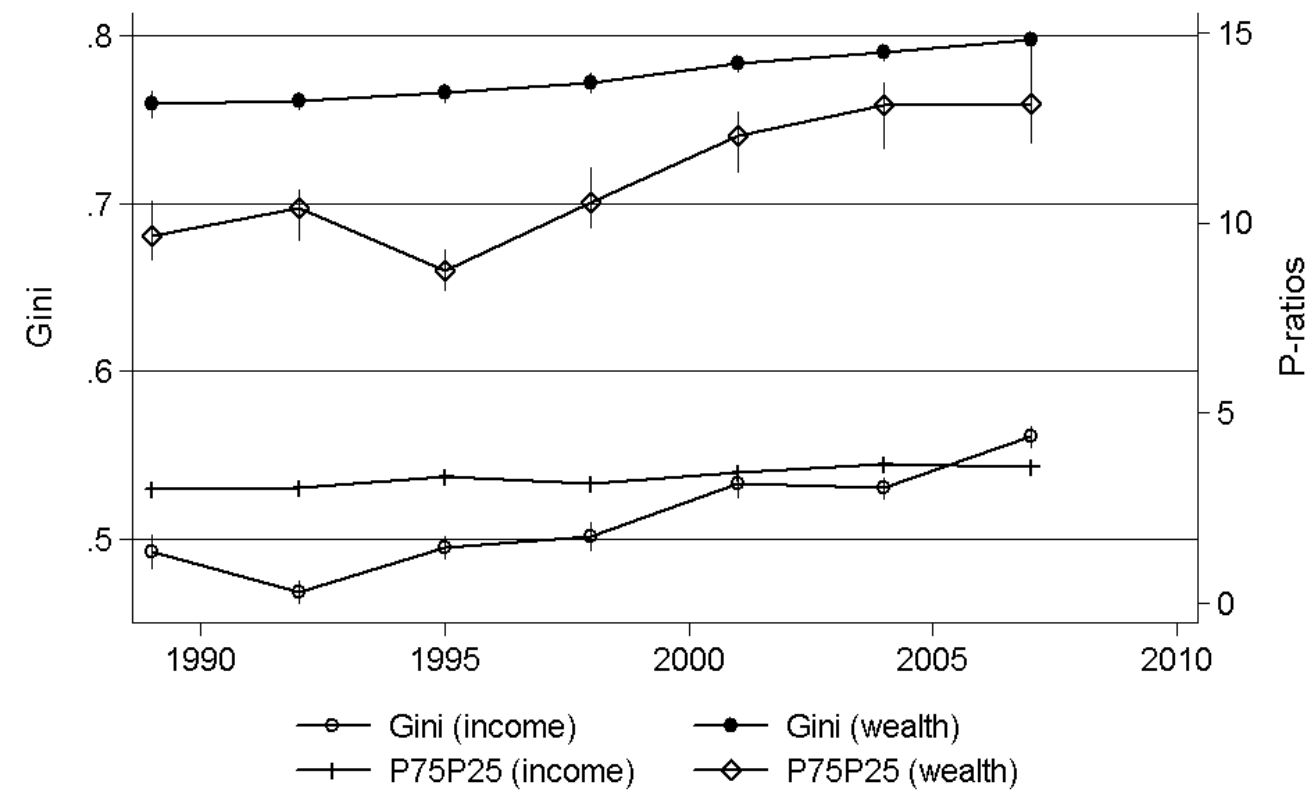

Source: SCF 1989-2007, own calculations.

Confidence intervals $(95 \%)$ based on 500 bootstrap replications.

Figure B.8: Inequality over time in the US 


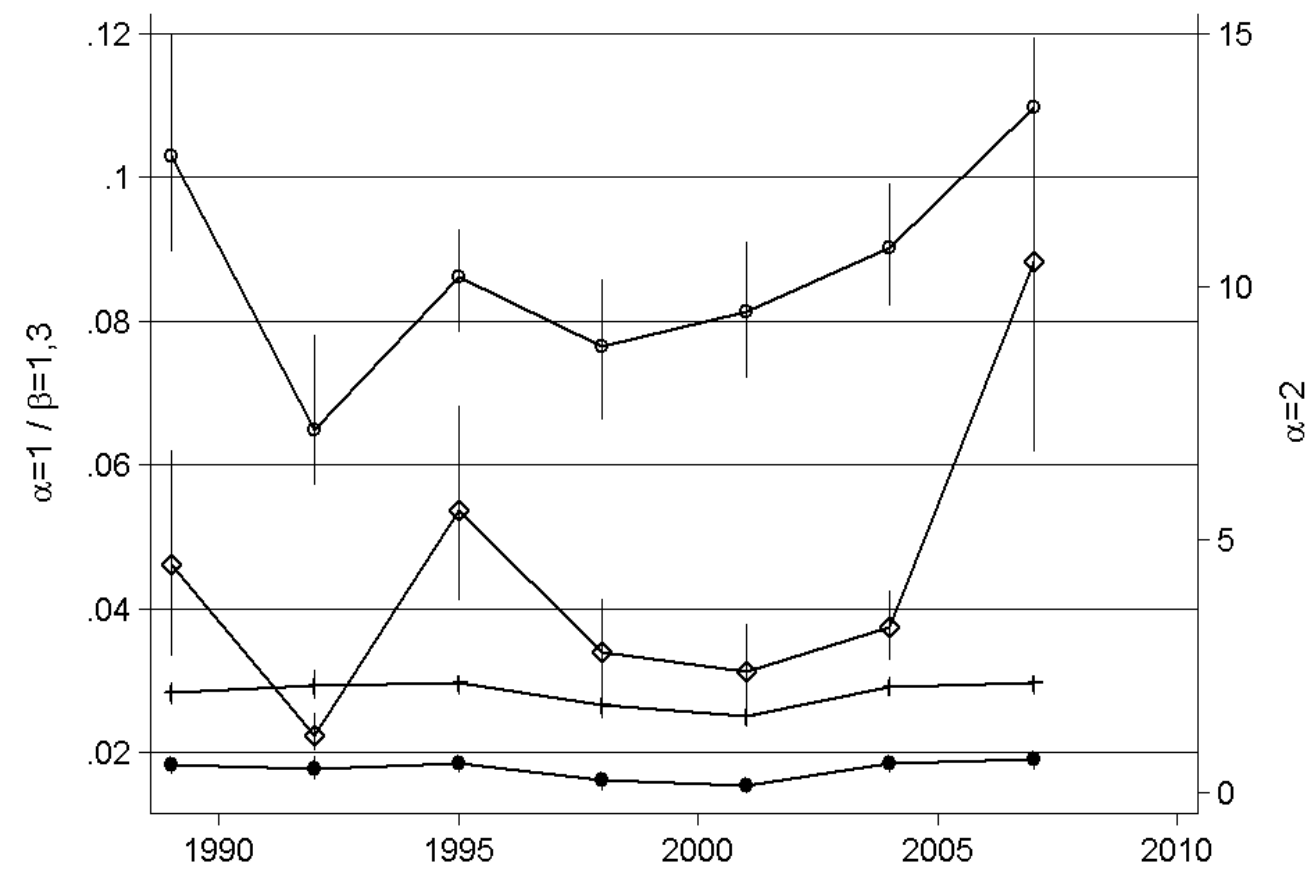

(a) Income

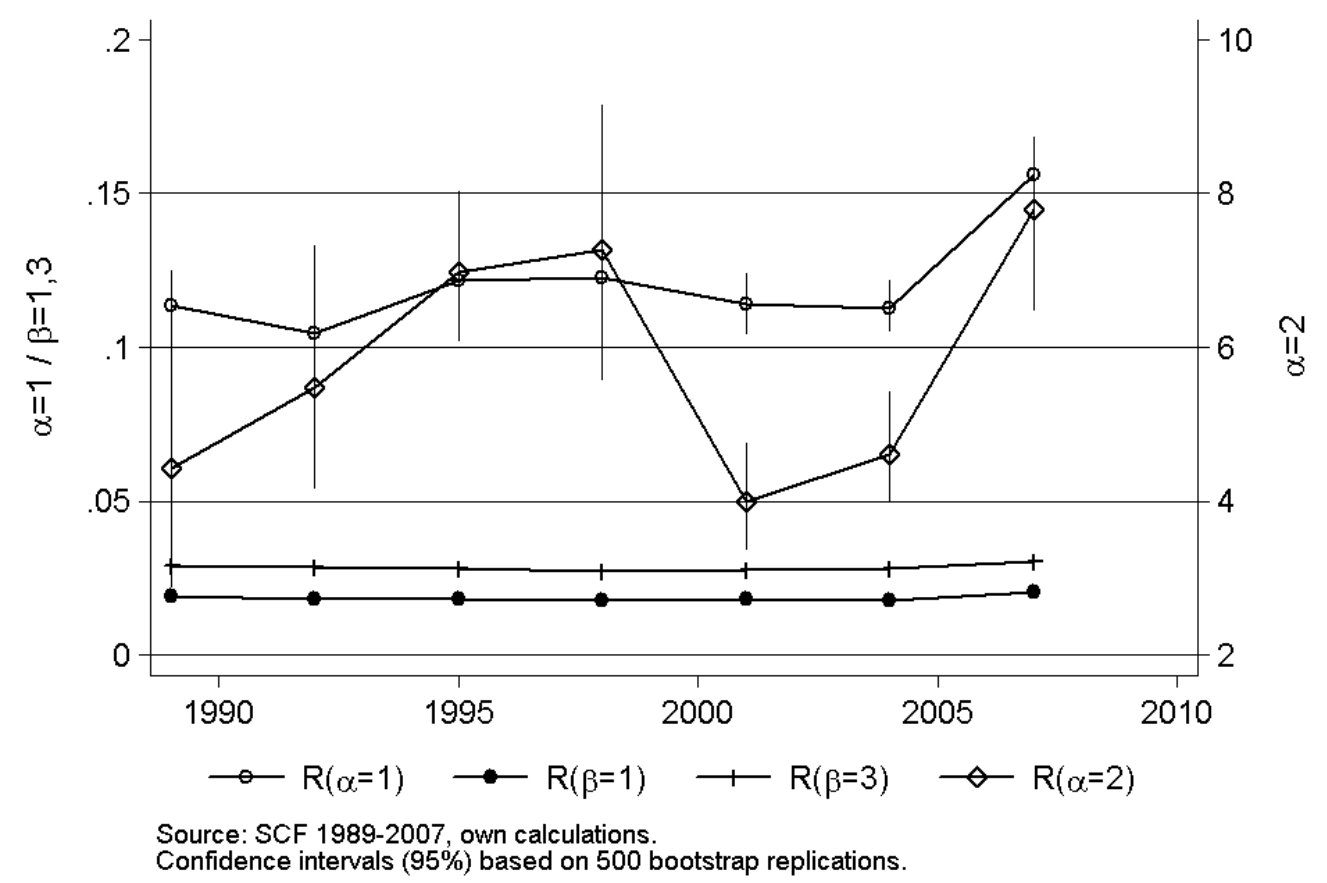

(b) Wealth

Figure B.9: One-dimensional affluence in the US 


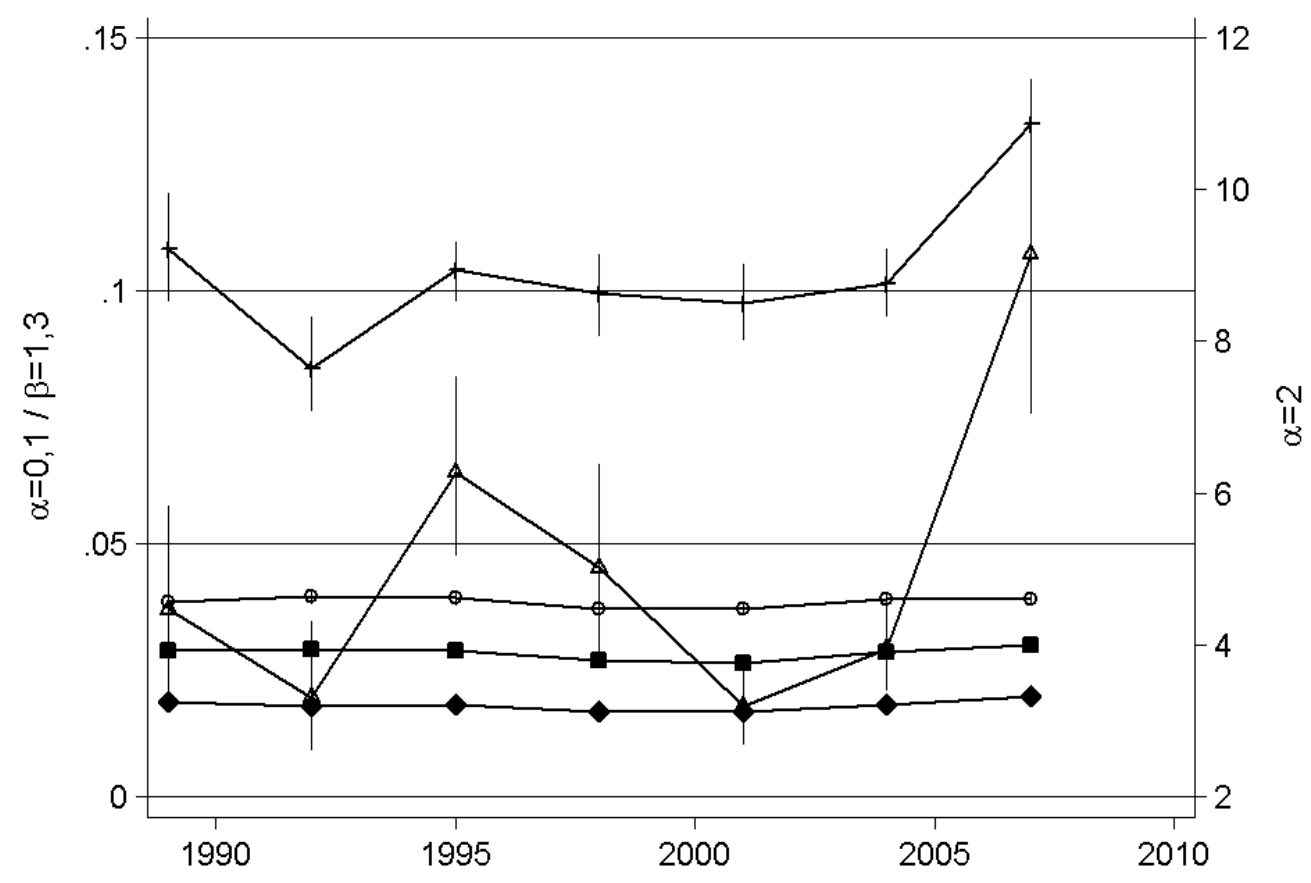

(a) $k=1$

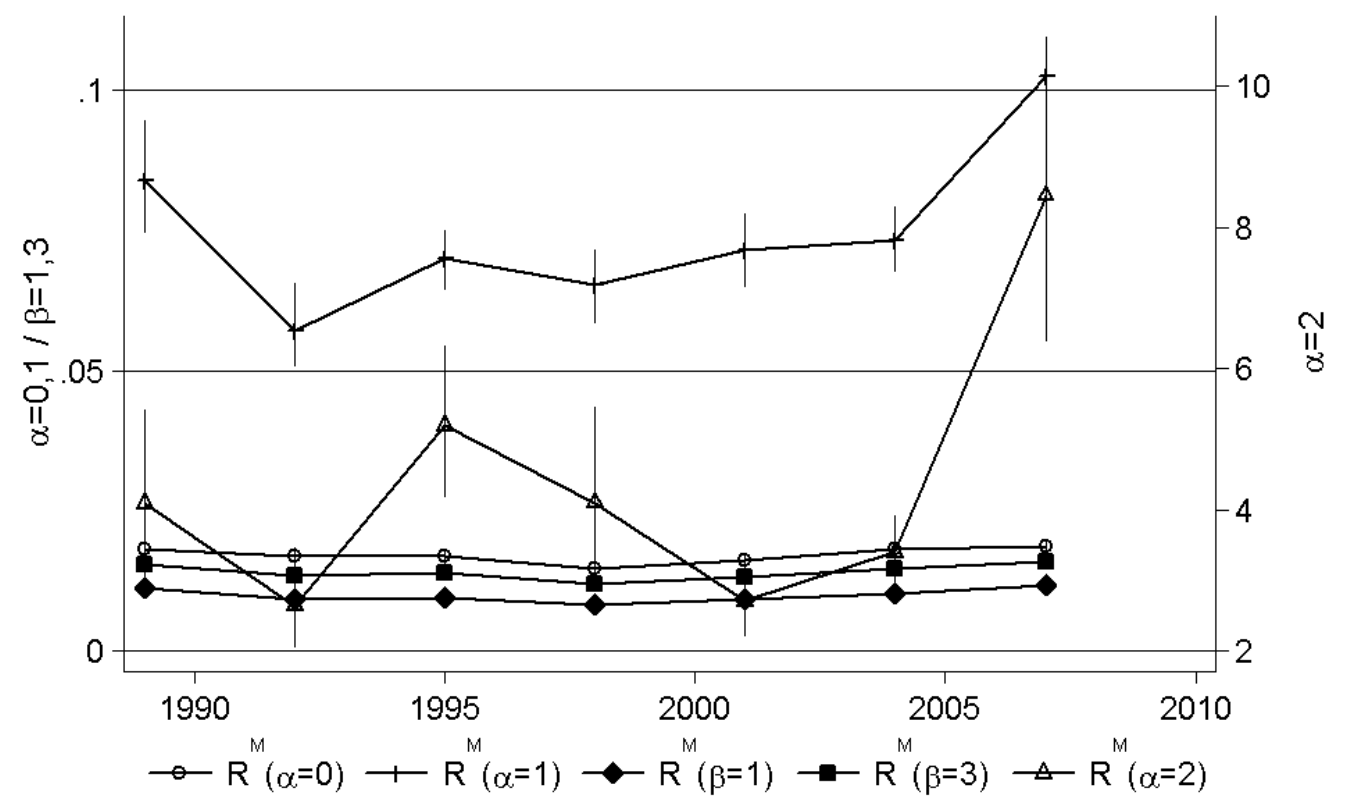

Source: SCF 1989-2007, own calculations.

Confidence intervals $(95 \%)$ based on 500 bootstrap replications.

(b) $k=2$

Figure B.10: Multidimensional affluence in the US 


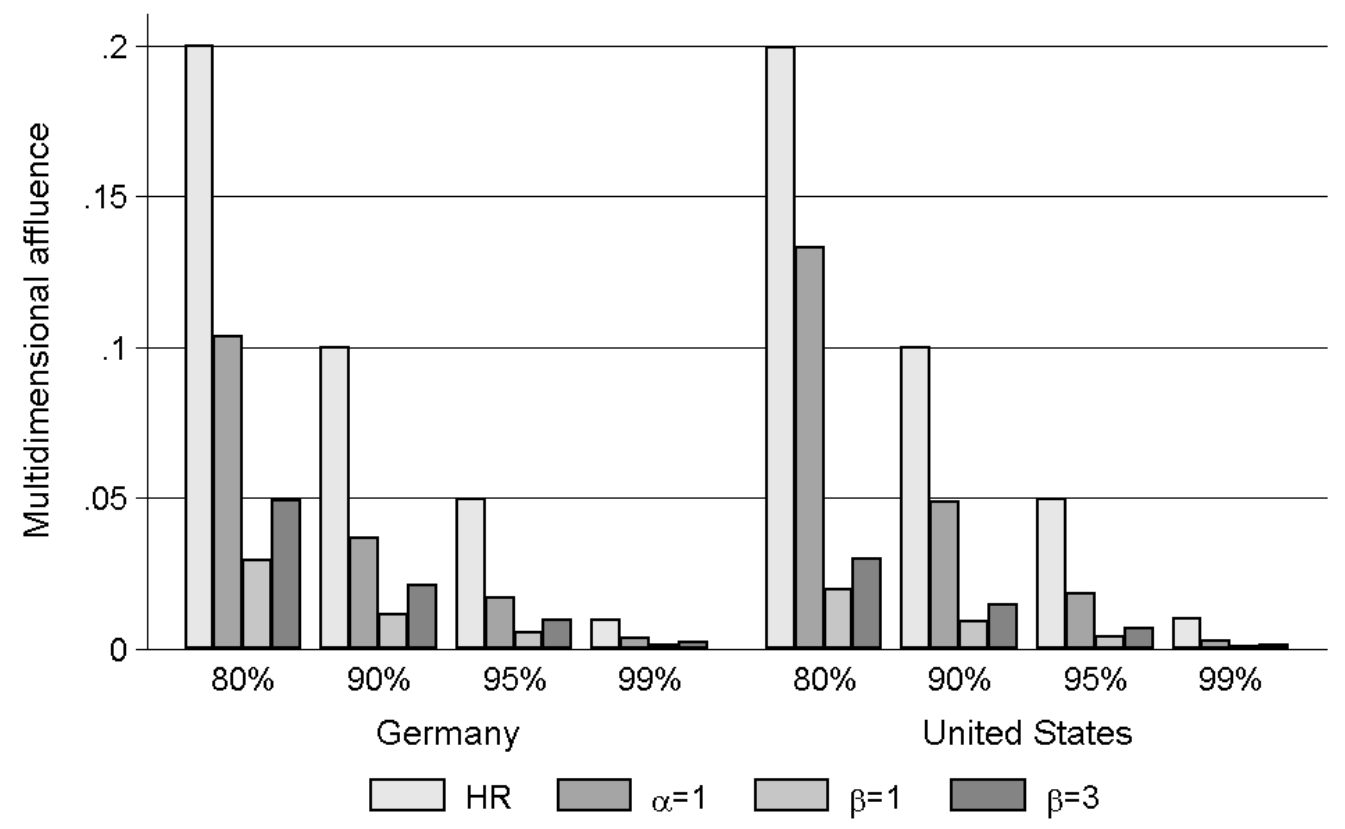

Source: SOEP/SCF 2007, own calculations.

(a) $k=1$

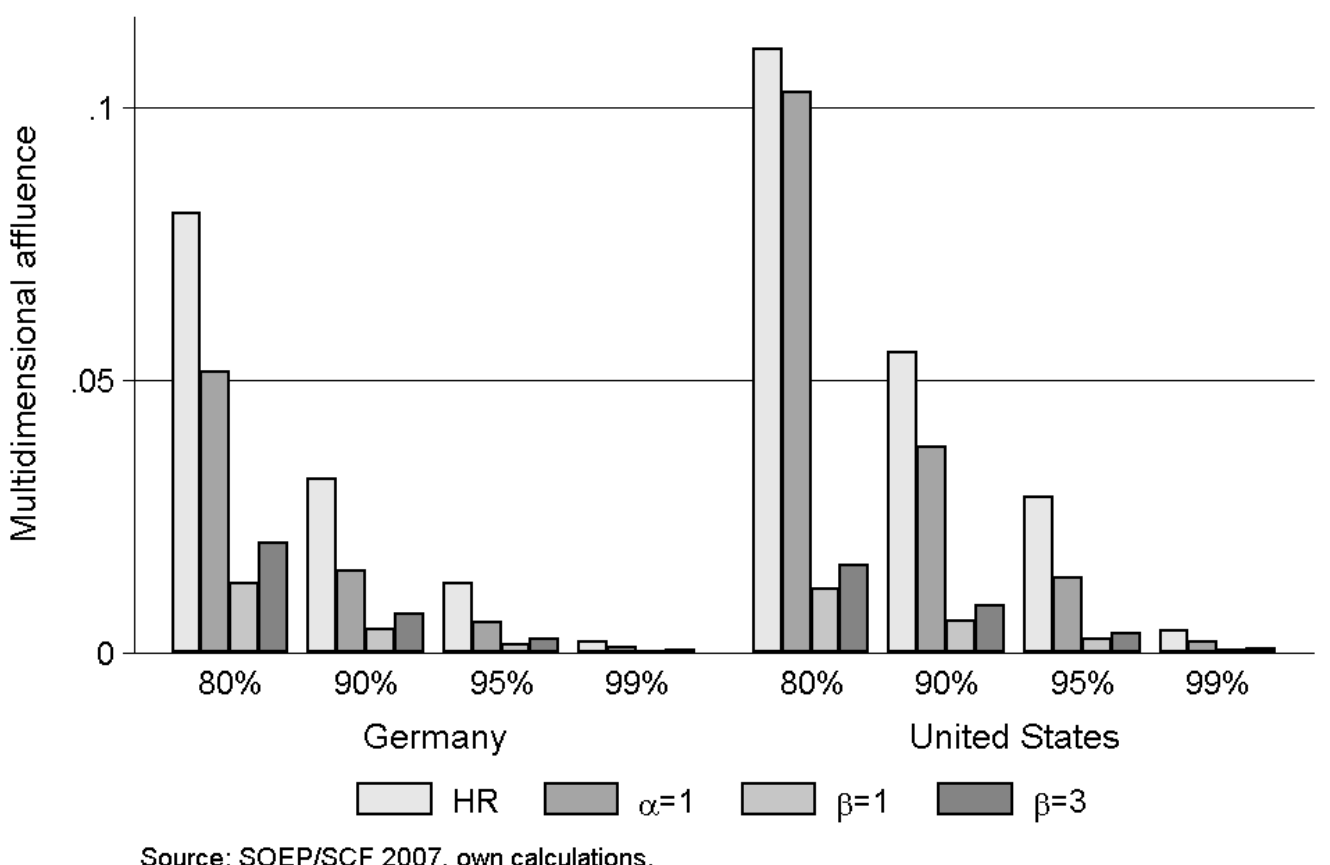

(b) $k=2$

Figure B.11: Multidimensional affluence for different cutoff levels 


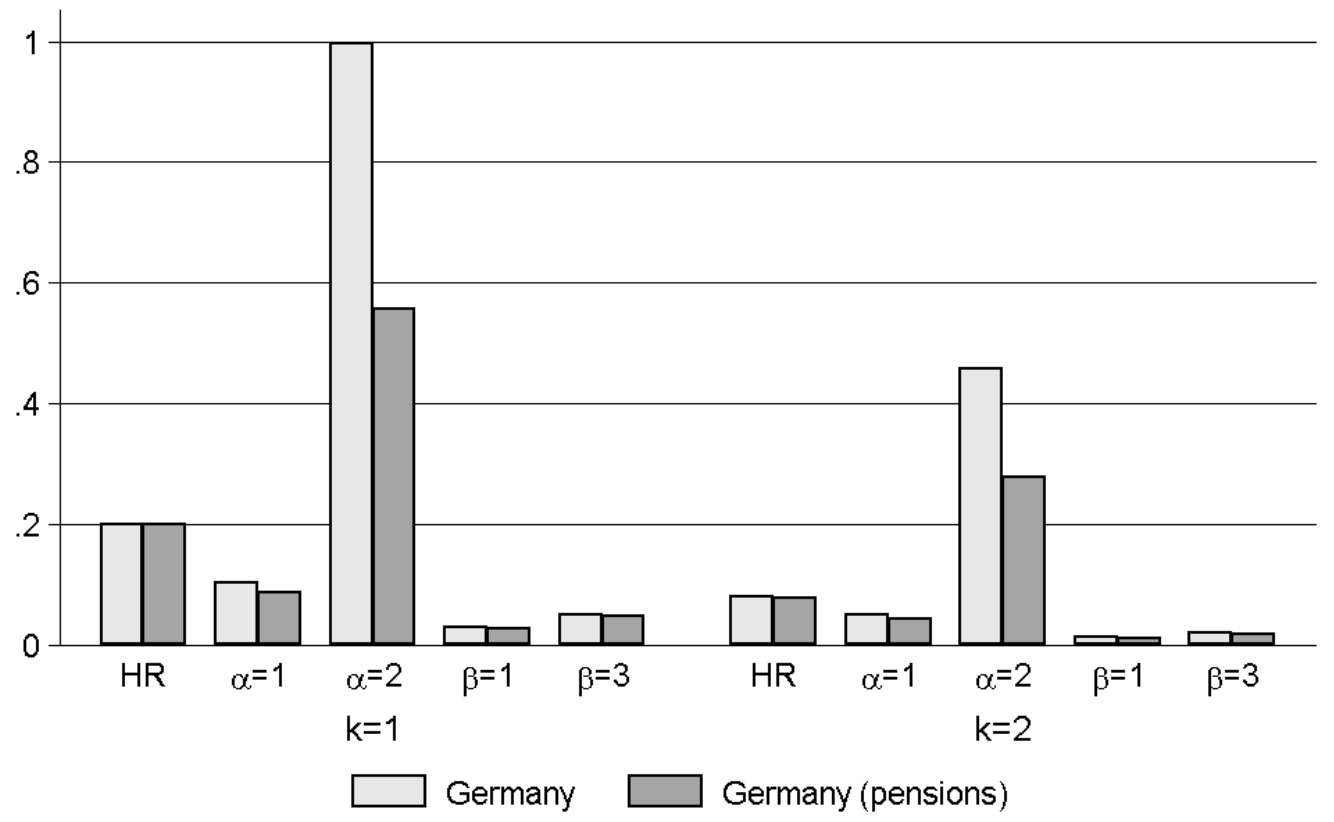

Source: SOEP and Rasner, Frick and Grabka (2011), own calculations.

Figure B.12: Multidimensional affluence with and without public pension wealth 


\section{Weighting of dimensions}

In section 2.2 we described the measurement of multidimensional affluence in the case of equal weighting of dimensions. Here, we describe the more general case with different weights $w_{j}$ for dimensions $j$, where it holds that the weights sum up to the number of dimensions under consideration $\left(\sum_{j=1}^{d} w_{j}=d\right)$. So far we have assumed $w_{j}=1 \forall j$. The identification of the dimension-specific affluent then becomes

$$
\theta_{i j}^{w}\left(y_{i j} ; \gamma\right)= \begin{cases}w_{j} & \text { if } y_{i j}>\gamma_{j} \\ 0 & \text { otherwise }\end{cases}
$$

and the sum of individual $i$ 's affluent dimensions' weights $c_{i}^{w}=\sum_{j=1}^{d} \theta_{i j}^{w}$ is needed for the identification of multidimensional richness depending on the second-stage cutoff $k \in\left[\min _{j}\left(w_{j}\right), d\right]:$

$$
\phi_{i}^{k, w}\left(y_{i}, \gamma\right)= \begin{cases}1 & \text { if } c_{i}^{w} \geq k \\ 0 & \text { if } c_{i}^{w}<k\end{cases}
$$

Hence, the weighted matrices now read

$$
\boldsymbol{\Theta}^{\alpha, \mathbf{w}}(\mathbf{k})=\left[w_{j} \cdot\left(\frac{y_{i j}-\gamma_{j}}{\gamma_{j}}\right)^{\alpha} \cdot \phi_{i}^{k, w}\left(y_{i}, \gamma\right)\right]_{n \times d}
$$

and

$$
\boldsymbol{\Theta}^{\beta, \mathbf{w}}(\mathbf{k})=\left[w_{j} \cdot\left(1-\left(\frac{\gamma_{j}}{y_{i j}}\right)^{\beta}\right) \cdot \phi_{i}^{k, w}\left(y_{i}, \gamma\right)\right]_{n \times d}
$$

respectively. The calculation of the multidimensional affluence measures and its contributions now works in the same as in the equal weighting case before. 


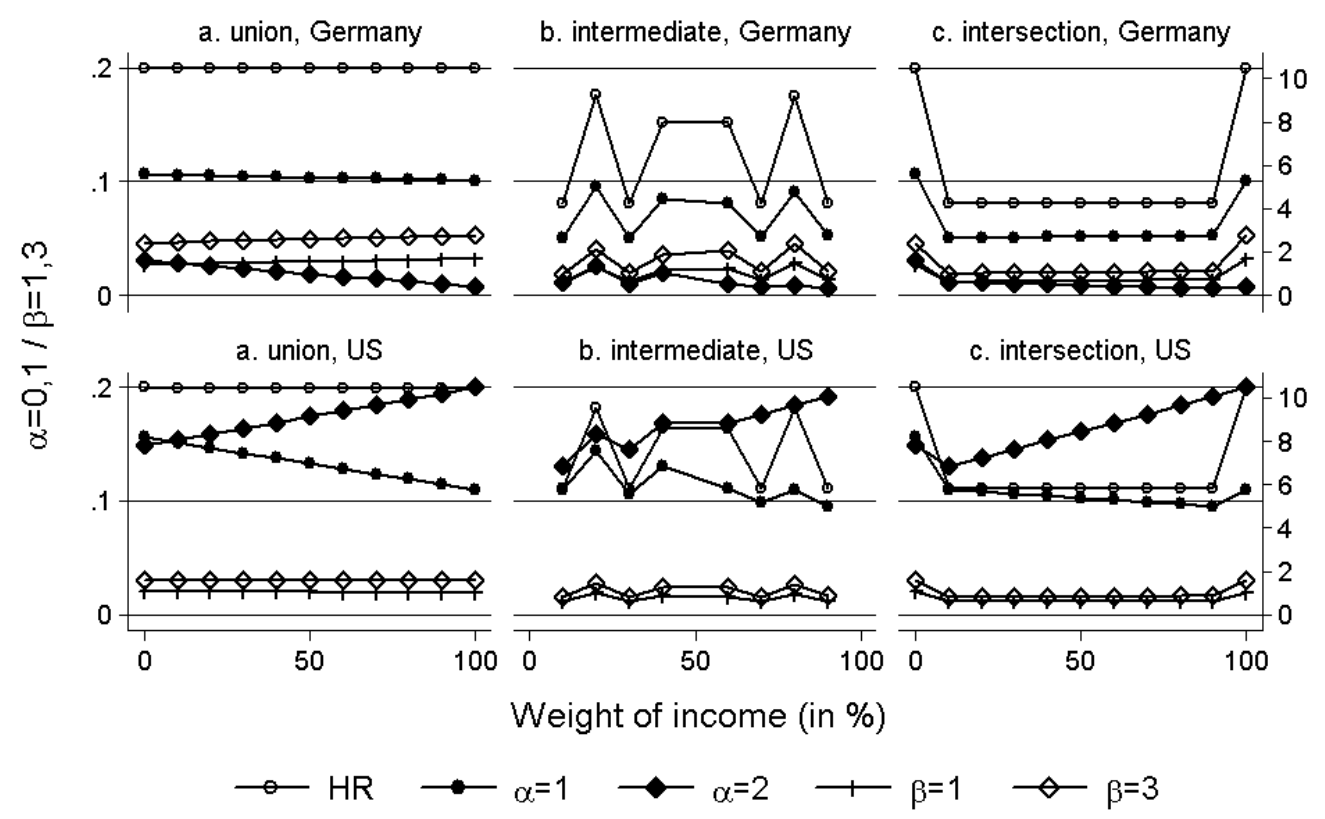

Source: SOEP/SCF 2007, own calculations.

Figure C.13: Multidimensional affluence for different weights

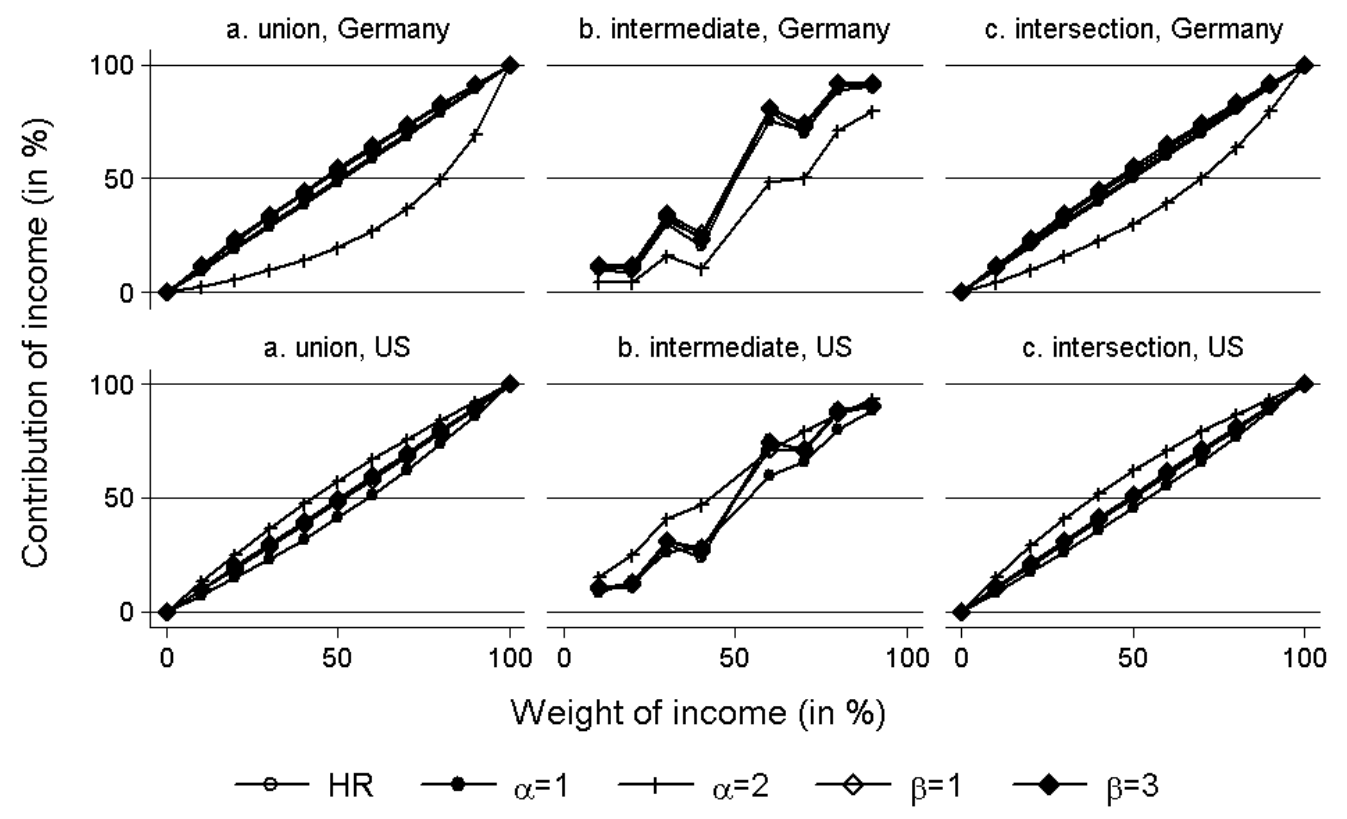

Source: SOEP/SCF 2007, own calculations.

Figure C.14: Dimension-specific contributions for different weights 